\title{
Fe-carbon nitride "Core-shell" electrocatalysts for the oxygen reduction reaction
}

\author{
Keti Vezzù ${ }^{\mathrm{a}, \mathrm{b}}$, Antoine Bach Delpeuch ${ }^{\mathrm{a}}$, Enrico Negro ${ }^{\mathrm{a}, \mathrm{b}, \mathrm{c}}$, Stefano Polizzi ${ }^{\mathrm{d}}$, \\ Graeme Nawn ${ }^{a}$, Federico Bertasi ${ }^{a}$, Gioele Pagot ${ }^{\mathrm{a}, \mathrm{c}}$, Kateryna Artyushkova ${ }^{\mathrm{e}}$, \\ Plamen Atanassov ${ }^{\mathrm{e}}$, Vito Di Noto ${ }^{\mathrm{a}, \mathrm{b}, \mathrm{f}, *}$
}

\author{
a Section of "Chemistry for the Technology" (ChemTec), Department of Industrial Engineering, University of Padova, in the Department of Chemical Sciences, \\ Via Marzolo 1, I-35131 Padova (PD), Italy \\ ${ }^{\mathrm{b}}$ Consorzio Interuniversitario per la Scienza e la Tecnologia dei Materiali (INSTM), Italy \\ ' Centro Studi di Economia e Tecnica dell'Energia "Giorgio Levi Cases», 35131 Padova (PD), Italy \\ ' Department of Molecular Sciences and Nanosystems and Centre for Electron Microscopy “G. Stevenato”, University Ca' Foscari Venice, Via Torino 155/B, I- \\ 30172 Venezia-Mestre (VE), Italy \\ e Department of Chemical and Biological Engineering, and Center for Micro-Engineered Materials University of New Mexico, Albuquerque, NM, USA \\ ${ }^{\mathrm{f}}$ CNR-ICMATE, Via Marzolo 1, I-35131 Padova (PD), Italy
}

\section{A R T I C L E I N F O}

\section{Article history:}

Received 10 July 2016

Received in revised form 12 November 2016

Accepted 16 November 2016

Available online 18 November 2016

\section{Keywords:}

Fe-carbon nitride based electrocatalysts

Fe-N-C Platinum Group Metal-free catalysts

Oxygen reduction reaction

"Core-shell" morphology

Powder X-ray diffraction

CV-TF-RRDE method

\section{A B S T R A C T}

In this report, the preparation of Fe-carbon nitride $(\mathrm{CN})$-based electrocatalysts (ECs) with a "core-shell" morphology for the oxygen reduction reaction (ORR) is described. The ECs consist of spherical XC-72R carbon nanoparticles, the "cores", that are covered by a CN matrix, the "shell", that embeds Fe species in "coordination nests". The latter consist of hollow cavities in the CN matrix, whose internal surface is covered by $\mathrm{N}$ - and $\mathrm{C}$-ligands able to stabilize alloy nanoparticles or active sites. Two families of CN-based ECs are prepared, which are grouped on the basis of the concentration of $\mathrm{N}$ atoms in the $\mathrm{CN}$ "shell". Each group comprises of both a "pristine" and an "activated" EC; the latter is obtained from the "pristine" EC by a suitable series of treatments (A) devised to improve the ORR performance. The chemical composition of the $\mathrm{CN}$-based ECs is determined by Inductively-Coupled Plasma Atomic Emission Spectroscopy (ICP-AES) and microanalysis. The thermal stability under both inert and oxidizing atmospheres is gauged by HighResolution Thermogravimetric Analysis (HR-TGA). The structure is probed by powder X-ray diffraction, and the morphology is inspected by Scanning Electron Microscopy (SEM) and High-Resolution Transmission Electron Microscopy (HR-TEM). The surface area of the CN-based ECs is determined by nitrogen physisorption techniques, and the surface composition is probed by X-ray Photoelectron Spectroscopy (XPS). The electrochemical performance and reaction mechanism of the CN-based ECs in the ORR is investigated in both acid and alkaline environments by cyclic voltammetry with the Thin-Film Rotating Ring-Disk Electrode setup (CV-TF-RRDE). The influence of the preparation parameters and of the treatments on the physicochemical properties, the ORR performance, and reaction mechanism is studied in detail. In the alkaline environment the $\mathrm{FeFe}_{2}-\mathrm{CN}_{1} 900 / \mathrm{C}_{\mathrm{A}}$ "core-shell" EC shows a remarkable ORR onset potential of $0.908 \mathrm{~V}$ vs. RHE which, with respect to the value of $0.946 \mathrm{~V} v s$. RHE of the Pt/C ref., classifies the proposed materials as very promising "Platinum Group Metal-free" ECs for the ORR.

(C) 2016 Elsevier Ltd. All rights reserved.

\section{Introduction}

As of today, one of the most important global challenges is the necessity to renovate completely the infrastructure required to harness and distribute energy [1-3]. New environment-friendly

\footnotetext{
* Corresponding author.

E-mail address: vito.dinoto@unipd.it (V. Di Noto).
}

technologies must be implemented on a large scale to curtail the emissions of greenhouse gases and reduce the dependency on nonrenewable energy sources [1]. To achieve these goals, electrochemical energy conversion and storage systems are expected to play a continually increasing role owing to their high efficiency and flexibility $[3,4]$. In particular, low-temperature fuel cells (FCs) and metal-air batteries have attracted considerable interest due to their high energy and power densities [5-7], thus making them 
suitable for small stationary systems [8], the automotive sector [9-11] and portable electronics [12,13].

The operation of both metal-air batteries and low-temperature FCs is bottlenecked by the sluggish kinetics of the oxygen reduction reaction (ORR) [14,15]. In the case of low-temperature fuel cells, until very recently, the only viable electrolytes were protonconducting systems (e.g., perfluorinated ionomers such as Nafion ${ }^{\circledR}$, Hyflon-Ion ${ }^{\circledR}, 3 \mathrm{M}$ polymer, hydrocarbon-based membranes, among many others) [16], giving rise to a highly acidic environment at the electrodes. Accordingly, low-temperature FCs had to rely on ORR electrocatalysts (ECs) containing a high loading of platinum-group metals (PGMs) in order to achieve a performance and durability level compatible with the applications $[17,18]$. The latter is one of the main reasons why the large-scale rollout of low-temperature fuel cells (e.g., proton-exchange membrane fuel cells, PEMFCs, and direct methanol fuel cells, DMFCs) has not been realized. In recent years, significant progress has been achieved in the development of advanced anion-exchange membranes (AEMs) allowing the facile diffusion of $\mathrm{OH}^{-}$anions $[19,20]$. These systems generate a strongly alkaline environment at the electrodes, which is able to provide a promising ORR kinetics by means of "Pt-free" ECs [21-23]. The latter are mostly based on common transition metals, thus lowering the risk of supply bottlenecks [24]. These benefits have prompted significant research efforts, aimed at developing high-performance, "Pt-free" ECs for the alkaline environment $[25,26]$.

There is a multitude of synthetic approaches to obtain "Pt-free" ORR electrocatalysts for the alkaline environment. A broad family of ECs includes the pyrolysis of precursors obtained by: (a) the chemical modification of carbon nanostructures (e.g., carbon nanoparticles [27], carbon nanotubes [28,29], graphene sheets [30,31]); and (b) natural materials (e.g., blood biomass [29], or eggs [32]). Other ECs are prepared by supporting on carbon black active sites based on inorganic compounds such as oxides [33], sulfides [34], selenides [35] and many others. It should be pointed out that in the last decade, a unique and highly flexible synthetic protocol was devised, and later improved, in our laboratory [36-38], which allowed for the preparation of two generations of metal alloy carbon nitride ECs. The first generation includes ECs based on small metal alloy nanoparticles (NPs) embedded in carbon nitride (CN) matrices of larger NPs $[39,40]$. The $\mathrm{CN}$ matrix consists of graphitic materials where a small amount of carbon atoms is substituted by $\mathrm{N}$ which, in the samples of Ref. 39 and 40, is on the order of $c a .5 .7$ at $\%$ or less $[39,40]$. The second generation groups the "core-shell" morphology ECs (CsECs). CsECs consist of a matrix of CN material, the "shell", which is wrapping homogeneously conductive NPs, the "core" [38,41,42]. Crucial in the preparation of these two generations of ECs is the synthesis of precursors, which in both cases are typically based on a suitable Zeolitic Inorganic-Organic Polymer Electrolyte (Z-IOPE). The latter is synthesized as reported elsewhere through a sol-gel and gel-plastic transition [37,39]. The Z-IOPE precursor consists of a 3D hybrid inorganic-organic crosslinked system, where clusters of the desired metals are bonded together through bridges of a suitable binder [38]. The multi-step pyrolysis process of the Z-IOPE precursors plays a crucial role in the modulation of the chemical composition and of the morphology of the active sites of the CN-based ECs [43]. It was proven that the CN-based ECs show an outstanding ORR performance in an acid environment, both "ex-situ" and at the cathode of a single PEMFC $[37,44,45]$. The active sites are typically located on the surface of alloy NPs coordinated by the nitrogen and carbon ligands of the "coordination nests" of the CN matrix $[42,44,46]$. In the CN-based ECs, the alloy NPs bearing the active sites are stabilized in highly conducting $\mathrm{CN}$ matrices where the concentration of $\mathrm{N}$ atoms is lower than $5 \mathrm{wt} \%$. Most of these $\mathrm{N}$ atoms are located in the "coordination nests" of the alloy NPs
[37,38]. In this way, CN-based ECs with a high dispersion of the active sites are easily obtained, which address the issues associated with the mass transport of reactants and products towards and from the active sites of the ECs. In ECs of the proposed composition, a good electrical contact between active sites and the external circuit is guaranteed by the CN matrix $[37,38,44]$.

This report for the first time describes the preparation protocol devised and optimized to synthesize ORR Fe-CN-based ECs: (i) demonstrating the feasibility of the proposed preparation protocol to obtain highly active "Pt-free" ORR electrocatalysts for the alkaline environment; and (ii) elucidating the complex interplay existing between the preparation parameters, the activation process $(\mathbf{A})$, the physicochemical properties and the electrochemical performance of the resulting "core-shell" Fe-CNbased ECs.

\section{Experimental}

\subsection{Reagents}

Potassium hexacyanoferrate (II) trihydrate (98\%) and iron (III) chloride (97\%) are both purchased from Sigma-Aldrich. Sucrose, molecular biology grade is Alfa Aesar reagent. Perchloric acid (67$72 \%$ ), hydrofluoric acid (48 wt\%) and potassium hydroxide (98.4\%) are provided by Fluka Analytical, Sigma-Aldrich and VWR International. Isopropanol (>99.8\%) is received from Sigma-Aldrich. All chemicals are used as received, without any further purification procedure. Doubly distilled water is used in all the experiments. EC-10 electrocatalyst is procured from ElectroChem, Inc. (nominal Pt loading: $10 \mathrm{wt} \%$ ); it is labeled "Pt/C ref." throughout the text. XC-72R is supplied by Carbocrom S.r.l. and is washed with $\mathrm{H}_{2} \mathrm{O}_{2}$ (10 vol.\%) prior to use.

\subsection{Synthesis of the electrocatalysts}

The synthesis of the new Fe-CN-based ECs, which is inspired by the preparation protocol previously reported [47], is discussed in the following text. $\mathrm{FeCl}_{3}(487 \mathrm{mg}$ ) is dissolved in a minimum amount of water $(\sim 2 \mathrm{~mL})$. To this sample is added: (i) in a first step, a viscous solution prepared mixing $1820 \mathrm{mg}$ of sucrose to $\mathrm{ca} .2 \mathrm{~mL}$ of water; and (ii) in a second step, $1820 \mathrm{mg}$ of XC-72R nanoparticles. The resulting suspension (Suspension I) is finally homogenized by probe sonication. A second suspension (Suspension II) is prepared as above described, using $2534 \mathrm{mg}$ of $\mathrm{K}_{4} \mathrm{Fe}$ $(\mathrm{CN})_{6} \cdot 3 \mathrm{H}_{2} \mathrm{O}$ in place of $\mathrm{FeCl}_{3}$. Suspension I and Suspension II are mixed, thoroughly homogenized by probe sonication, and allowed to rest for 2 days. The resulting product is dried in an oven at $120^{\circ} \mathrm{C}$ and transferred into a quartz tube, where it undergoes a three-step pyrolysis process under dynamic vacuum as follows: Step $1: 150^{\circ} \mathrm{C}$, 7 hours; Step 2: $300^{\circ} \mathrm{C}, 2$ hours; Step III: $900^{\circ} \mathrm{C}, 2$ hours. The resulting product is divided into two aliquots, labeled $\mathrm{A}$ and $\mathrm{B}$. A is washed three times with water, yielding the "pristine" $\mathrm{CN}$-based EC. B undergoes the "activation process" (indicated as A in the following text), which consists of: (a) an etching step with $10 \mathrm{wt} \%$ hydrofluoric acid (HF) lasting two hours, followed by an extensive washing with water; and (b) a pyrolysis step under dynamic vacuum at $900^{\circ} \mathrm{C}$ lasting two hours. The resulting product is the "activated" CN-based EC. The protocol above is used to obtain two groups of $\mathrm{CN}$-based ECs. In the first group, the molar ratio between $\mathrm{FeCl}_{3}$ and $\mathrm{K}_{4} \mathrm{Fe}(\mathrm{CN})_{6} \cdot 3 \mathrm{H}_{2} \mathrm{O}$ is $1: 2$; accordingly, the resulting "pristine" and "activated" $\mathrm{CN}$-based ECs are labeled " $\mathrm{FeFe}_{2}-\mathrm{CN}_{l}$ $900 / C$ " and " $\mathrm{FeFe}_{2}-\mathrm{CN}_{l} 900 / C_{A}$ ", respectively. In the second group, the molar ratio between $\mathrm{FeCl}_{3}$ and $\mathrm{K}_{4} \mathrm{Fe}(\mathrm{CN})_{6} \cdot 3 \mathrm{H}_{2} \mathrm{O}$ is $2: 1$; and the synthesis is carried out exactly as above, with the difference that the amounts of $\mathrm{FeCl}_{3}$ and $\mathrm{K}_{4} \mathrm{Fe}(\mathrm{CN})_{6} \cdot 3 \mathrm{H}_{2} \mathrm{O}$ are 974 and $1267 \mathrm{mg}$, respectively. In this latter group, the "pristine" and "activated" 
CN-based ECs are labeled " $\mathrm{Fe}{ }_{2} \mathrm{Fe}-\mathrm{CN}_{l} 900 / \mathrm{C}$ " and " $\mathrm{Fe}{ }_{2} \mathrm{Fe}-\mathrm{CN}_{l} 900 / \mathrm{C}_{A}$ ", respectively.

\subsection{Instruments and methods}

The assay of $\mathrm{C}, \mathrm{H}, \mathrm{N}$, and $\mathrm{S}$ is determined by elemental analysis using an FISONS EA-1108 CHNS-O instrument. The wt\% of Fe and $\mathrm{K}$ is assessed by Inductively-Coupled Plasma Atomic Emission Spectroscopy (ICP-AES) carried out by means of a SPECTRO Arcos spectrometer with EndOnPlasma torch. The digestion of the samples is described elsewhere [40]. The emission lines are: $\lambda$ $(\mathrm{Fe})=259.940 \mathrm{~nm}, \lambda(\mathrm{K})=766.490 \mathrm{~nm}$. High-Resolution Thermogravimetric Analyses (HR-TGA) are conducted in the temperature range between 30 and $1000^{\circ} \mathrm{C}$ using a TGA 2950 analyzer (TA instruments). The sensitivity of the instrument ranges from 0.1 to $2 \% \cdot \mathrm{min}^{-1}$; the resolution is $1 \mu \mathrm{g}$. The heating rate is varied on the basis of the first derivative of the weight loss from 50 to $0.001{ }^{\circ} \mathrm{C} \mathrm{min}^{-1}$. The measurements are performed with an open Pt pan, both in an inert $\left(\mathrm{N}_{2}\right)$ and in an oxidizing (air) atmosphere. Powder X-ray profiles are collected with a GNR diffractometer (mod. eXplorer) mounting a monochromatized CuK $\alpha$ source in the $2 \theta$ range $3-70^{\circ}$ with a $0.05^{\circ}$ step and integration time of $40 \mathrm{sec}$. The XRD profiles are analyzed with the MAUD software [48]. A Cambridge Stereoscan 250 Mark 1 scanning electron microscope, operating at an acceleration voltage of $20 \mathrm{kV}$, is used to collect standard images with backscattered electrons. Both conventional and high-resolution transmission electron microscopy studies are carried out with a Jeol 3010 apparatus equipped with a highresolution pole piece $(0.17 \mathrm{~nm}$ point-to-point resolution) and a Gatan slow-scan 794 CDD camera. The preparation of the samples takes place in accordance with a protocol described elsewhere [44]. XPS spectra are collected at a Kratos Axis DLD Ultra X-ray photoelectron spectrometer using an $\mathrm{Al} \mathrm{K} \alpha$ monochromatic source operating at $150 \mathrm{~W}$ with no charge compensation. The base pressure is ca. $2 \cdot 10^{-10} \mathrm{Torr}$; the operating pressure is $c a .2 \cdot 10^{-9}$ Torr. Survey and high-resolution spectra are acquired at pass energies of 80 and $20 \mathrm{eV}$, respectively. Acquisition time for survey spectra is $3 \mathrm{~min}$; in the case of high-resolution spectra, the acquisition time is $2 \mathrm{~min}$ for $\mathrm{C} 1 \mathrm{~s}, 5 \mathrm{~min}$ for $\mathrm{O} 1 \mathrm{~s}$, and $30 \mathrm{~min}$ for both $\mathrm{N} 1 \mathrm{~s}$ and $\mathrm{Fe} 2 \mathrm{p}$ regions. The analysis and quantification of the data are carried out in CasaXPS. The $\mathrm{C} 1 \mathrm{~s}, \mathrm{O} 1 \mathrm{~s}$ and $\mathrm{N} 1 \mathrm{~s}$ spectra are quantified using linear background while Fe 2p using Shirley background subtraction. Sensitivity factors provided by the manufacturer are utilized. The curve-fit of $\mathrm{N}$ 1s spectra is done using a 70\% Gaussian/30\% Lorentzian line shape. The surface area of the samples is determined by a Micrometrics Gemini V system using a 5-points Brunauer-Emmett-Teller (BET) method.

\subsection{Electrochemical measurements}

The electrode inks are prepared following a protocol described in the literature [39]. Each electrode ink is deposited onto the glassy carbon $(\mathrm{GC})$ disk $(\varnothing 0.5 \mathrm{~cm})$ of the rotating ring-disk electrode (RRDE) tip. The total loading of CN-based EC on the GC disk of the RRDE tip is equal to $0.765 \mathrm{mg} \cdot \mathrm{cm}^{-2}$. In the case of the $\mathrm{Pt} / \mathrm{C}$ ref., the Pt loading is $15 \mu \mathrm{g}_{\mathrm{Pt}} \cdot \mathrm{cm}^{-2}$. Thus, the thickness of the electrode layers deposited on the RRDE tips can be estimated at $c a$. 7 and $0.65 \mu \mathrm{m}$ for the CN-based ECs and the Pt/C ref., respectively. The total loading of Nafion binder on the RRDE tips is on the order of $0.05 \mu \mathrm{g} \cdot \mathrm{cm}^{-2}$. This value is negligible in comparison to that of the ECs and does not provide an appreciable contribution to the thickness of the electrode layers. The electrochemical setup is described elsewhere [41]. Measurements in acid and alkaline environments are collected using as electrolyte a $0.1 \mathrm{M} \mathrm{HClO}_{4}$ and a $0.1 \mathrm{M} \mathrm{KOH}$ solution, respectively. The $\mathrm{Hg} / \mathrm{HgSO}_{4} / \mathrm{K}_{2} \mathrm{SO}_{4 \text { (sat.) }}$ and $\mathrm{Hg} /$ $\mathrm{HgO} / \mathrm{KOH}_{(\mathrm{aq})}(0.1 \mathrm{M})$ reference electrode for the acid and the alkaline environment, respectively, is placed in a separate compartment. All potentials are reported in terms of the reversible hydrogen electrode (RHE) scale. Calibration is carried out by $\mathrm{H}_{2}$ oxidation/reduction measurements on a platinized platinum electrode before each experiment. The rotating ring-disk working electrode is mounted on a Model 636 rotator (Pine Research Instrumentations). The collection efficiency of the Pt ring is equal to 0.38 . The data are collected with a multi-channel VSP potentiostat/galvanostat from Bio-Logic. CN-based ECs are activated electrochemically by cycling the $\mathrm{CN}$ electrode films between $E=0.05$ and $1.05 \mathrm{~V} v$ s. RHE in an $\mathrm{O}_{2}$-saturated $0.1 \mathrm{M} \mathrm{HClO}_{4}$ solution at a sweep rate $(v)$ of $100 \mathrm{mV} \mathrm{s}^{-1}$ and with a tip rotation of the RRDE electrode of $1600 \mathrm{rpm}$ until the voltammogram is stabilized. The electrochemical measurements are then collected at the same RRDE rotation rate and at $v=20 \mathrm{mV} \mathrm{s}^{-1}$. During the measurements, the ring electrode is always maintained at $E=1.2 \mathrm{~V} v \mathrm{~s}$. RHE to detect the hydrogen peroxide [49]. The faradic ORR currents are obtained measuring first the cyclic voltammogramms in the $\mathrm{N}_{2}$-saturated $0.1 \mathrm{HClO}_{4}$, and then subtracting these values from those collected under an oxygen atmosphere [50]. The contribution of the ohmic resistance of the electrochemical setup, which is evaluated after each measurement, is removed from the cyclic voltammograms [51]. To evaluate the activity of the CN-based ECs in different atmospheres, high purity nitrogen and oxygen gases (Air Liquide) are used to saturate the electrochemical cell. Tests in alkaline conditions are performed using the same procedure but with a $0.1 \mathrm{M} \mathrm{KOH}$ electrolyte solution. Current densities are obtained normalizing the disk currents to the GC geometric area.

\section{Results and Discussion}

The ORR performance of the proposed ECs is maximized by: (i) adopting a "core-shell" morphology with "cores" of spherical XC72R carbon black NPs and "shells" of CN matrix; (ii) introducing a low concentration of $\mathrm{N}$ in the $\mathrm{CN}$ matrix, to be mostly included in "coordination nests"; and (iii) taking advantage of $\mathrm{Fe}-\mathrm{CN}$-based coordination species to promote the electrochemical process. Two groups of $\mathrm{CN}$-based ECs are prepared, distinguished by the concentration of cyano ligands in the starting metal complexes. Each group of CN-based ECs comprises both a "pristine" and an "activated" material. Fe is studied owing to its ability to provide stable metal-carbon coordination bonds with the $\mathrm{CN}$ matrix and for its well-known capability to promote the ORR both in the acid and in the alkaline medium [52]. With the aim to improve the ORR performance, "activated" ECs (which include the subscript " $A$ " in the labels) are prepared by suitable treatments of "pristine" ECs to remove "non-active" Fe-based species and contaminants.

\subsection{Chemical Composition}

All the $\mathrm{CN}$-based ECs comprise a small wt\% of heteroatoms, i.e. hydrogen, nitrogen, and sulfur. The chemical analysis of the $\mathrm{CN}-$ based ECs is summarized in Table 1 . The presence of $\mathrm{H}$ suggests that the graphitization of the organic fraction of the precursor is incomplete despite the high temperature of the final step of the pyrolysis process $\left(\mathrm{T}_{\mathrm{f}}=900^{\circ} \mathrm{C}\right)[40]$. $\mathrm{N}$ is introduced in the $\mathrm{CN}$ "shell" matrix exclusively by the cyano ligands of the $\mathrm{K}_{4} \mathrm{Fe}(\mathrm{CN})_{6} \cdot 3 \mathrm{H}_{2} \mathrm{O}$ reagent complexes. On these bases, it is reasonable to assume that $\mathrm{N}$ is not homogeneously distributed throughout the "shell" matrix, but it is mostly located close the Fe species [36], which are thus stabilized in "coordination nests" of CN matrix based on C- and Nligands [44]. In accordance with the stoichiometry of the reagents, the $\mathrm{N}$ fraction in $\mathrm{FeFe}_{2}-\mathrm{CN}_{1} 900 / \mathrm{C}$ is almost twice that of $\mathrm{Fe}_{2} \mathrm{Fe}-\mathrm{CN}_{1}$ $900 / C$. Traces of sulfur are detected which, as expected, are introduced by the XC-72R support [53]. Indeed, the XC-72R support includes: (a) $0.85 \mathrm{wt} \%$ of $\mathrm{S}$ as determined by elemental 
Table 1

The chemical composition of the CN-based ECs.

\begin{tabular}{|c|c|c|c|c|c|c|c|}
\hline \multirow[t]{2}{*}{ Electrocatalyst } & \multicolumn{6}{|c|}{ Weight $/ \%$} & \multirow[t]{2}{*}{ Formula } \\
\hline & $\mathrm{K}^{\mathrm{a}}$ & $\mathrm{Fe}^{\mathrm{a}}$ & $C^{b}$ & $\mathrm{H}^{\mathrm{b}}$ & $\mathrm{N}^{\mathrm{b}}$ & $\mathrm{S}^{\mathrm{b}}$ & \\
\hline $\mathrm{FeFe}_{2}-\mathrm{CN}_{l} \mathrm{900} / \mathrm{C}$ & 0.95 & 8.8 & 73.5 & 0.47 & 0.74 & 0.36 & $\mathrm{~K}_{0.15}\left[\mathrm{FeC}_{38.8} \mathrm{H}_{2.96} \mathrm{~N}_{0.34} \mathrm{~S}_{0.07}\right]$ \\
\hline $\mathrm{FeFe}_{2}-\mathrm{CN}_{l} 900 / C_{A}$ & 0.77 & 3.3 & 88.9 & 0.28 & 0.33 & 0.34 & $\mathrm{~K}_{0.33}\left[\mathrm{FeC}_{125} \mathrm{H}_{4.70} \mathrm{~N}_{0.40} \mathrm{~S}_{0.18}\right]$ \\
\hline $\mathrm{Fe}_{2} \mathrm{Fe}-\mathrm{CN}_{1} 900 / \mathrm{C}$ & 0.62 & 9.6 & 80.7 & 0.33 & 0.38 & 0.43 & $\mathrm{~K}_{0.09}\left[\mathrm{FeC}_{39.1} \mathrm{H}_{1.90} \mathrm{~N}_{0.16} \mathrm{~S}_{0.08}\right]$ \\
\hline $\mathrm{Fe}_{2} \mathrm{Fe}-\mathrm{CN}_{l} 900 / C_{A}$ & 0.44 & 0.17 & 92.1 & 0.2 & 0.43 & 0.58 & $\mathrm{~K}_{3.70}\left[\mathrm{FeC}_{2519} \mathrm{H}_{65.2} \mathrm{~N}_{10.1} \mathrm{~S}_{5.9}\right]$ \\
\hline
\end{tabular}

a Determined by ICP-AES.

b Determined by microanalysis.

analysis; and (b) less than $0.1 \mathrm{wt} \%$ of Fe, as revealed by EDX analysis. After the extensive pyrolysis and washing processes of ECs, potassium is still present in the materials. This evidence demonstrates that negatively-charged Fe coordination complexes and alcoholate/carboxylate functional groups [42] are present in the CN "shell", which are neutralized by $\mathrm{K}^{+}$cations [40]. The presence of these ionic groups likely improves the hydrophilicity of the resulting ECs.

The concentration of Fe in both pristine ECs is very similar and is in accordance with the starting stoichiometry of the reagents, while A process significantly influences the stoichiometry of the ECs as follows: (a) the wt\% of $\mathrm{H}$ is reduced, witnessing an improvement in the graphitization of the "activated" ECs; (b) the wt\% of Fe rises in the order $\mathrm{Fe}_{2} \mathrm{Fe}-\mathrm{CN}_{1} 900 / \mathrm{C}_{\mathrm{A}}<\mathrm{FeFe}_{2}-\mathrm{CN}_{1} 900 / \mathrm{C}_{\mathrm{A}}$, in accordance with the trend of the wt\% of $\mathrm{N}$ in the corresponding pristine ECs (see Table 1). This result highlights that the N-based ligands of the "coordination nests" of CN matrix in pristine ECs act to stabilize the metal complexes (see Section 3.3 and Section 3.4). Indeed, after $\mathbf{A}$ process the Fe species less stabilized owing to coordination by $\mathrm{N}$ ligands in the "coordination nests" are easily removed by the etching with HF. Thus, the type and density of the $\mathrm{N}$-ligand species forming the "coordination nests" of $\mathrm{CN}$ matrices play a crucial role in the chemical stability of Fe NPs and of the Fecoordination complexes.

\subsection{HR-TG analyses}

The HR-TGA profiles reported in Fig. 1(a) and (b) allow us to study the thermal stability of the $\mathrm{CN}$-based ECs, Pt/C ref. and $\mathrm{XC}-72 \mathrm{R}$ carbon black in inert $\left(\mathrm{N}_{2}\right)$ and oxidizing (air) atmospheres.

It should be noticed that under an $\mathrm{N}_{2}$ atmosphere the thermal stability at $\mathrm{T}>600^{\circ} \mathrm{C}$ (see Fig. 1(a)) of the CN-based ECs is higher than that of the Pt/C ref. This evidence, which is in accordance with other studies [37], demonstrates that the presence of nitrogen in the CN matrix "shell" improves the thermal stability of ECs in the order: $\mathrm{Fe}_{2} \mathrm{Fe}-\mathrm{CN}_{1} 900 / \mathrm{C}<\mathrm{FeFe}_{2}-\mathrm{CN}_{1} 900 / \mathrm{C}$ (see Table 1). Two thermal events (I and II) are observed in the HR-TGA profiles of ECs (see Fig. 1(a)). Between ca. 550 and $700^{\circ} \mathrm{C}$, (I) is attributed to the decomposition of the $\mathrm{CN}$ "shell"; and (II), at T $>800^{\circ} \mathrm{C}$, is assigned to the degradation of the XC-72R "cores". (II) is promoted by the presence of metal species on the surface of the ECs. Moreover, A improves the thermal stability of ECs increasing the graphitization of the CN "shell" [37,44]. The mass loss at $\mathrm{T}<200^{\circ} \mathrm{C}$ is diagnostic of the hydrophilicity of the ECs, and corresponds to the elimination process of $\mathrm{H}_{2} \mathrm{O}$. As expected, the hydrophilicity of the ECs rises on the $\mathrm{N}$ concentration and decreases on $\mathbf{A}$, as follows: $\mathrm{XC}-72 \mathrm{R}<\mathrm{Pt} / \mathrm{C}$ ref. $<\mathrm{Fe}_{2} \mathrm{Fe}-\mathrm{CN}_{\mathrm{l}} 900 / \mathrm{C}_{\mathrm{A}}<\mathrm{FeFe}_{2}-\mathrm{CN}_{1} 900 / \mathrm{C}_{\mathrm{A}}<\mathrm{Fe}_{2} \mathrm{Fe}-\mathrm{CN}_{1} 900 / \mathrm{C}<$ $\mathrm{FeFe}_{2}-\mathrm{CN}_{1}$ 900/C.

In the oxidizing atmosphere, the main degradation event $T_{D}$ is detected between 400 and $680^{\circ} \mathrm{C} . \mathrm{T}_{\mathrm{D}}$ is associated to the oxidation of the carbon-based matrix (see Fig. 1(b)), and rises in the order: $T_{D}$ (Pt/C ref.) $\approx \mathrm{T}_{\mathrm{D}}\left(\mathrm{FeFe}_{2}-\mathrm{CN}_{1} 900 / \mathrm{C}\right)<\mathrm{T}_{\mathrm{D}}\left(\mathrm{Fe}_{2} \mathrm{Fe}-\mathrm{CN}_{1} 900 / \mathrm{C}\right)<\mathrm{T}_{\mathrm{D}}(\mathrm{XC}-$ $72 \mathrm{R}$ ). This behavior is easily explained if we consider that the $\mathrm{O}_{2}$ of air preferentially adsorbs on Fe complexes stabilized by N-ligands of the CN matrix, thus facilitating the combustion of the whole EC. Indeed, a higher density of N-ligands in "coordination nests" improves the oxophilicity and the concentration of the Fe-coordination species of the $\mathrm{CN}$ matrix. This confirms the result that the $\mathrm{N}$ concentration in ECs decreases in the order: $\mathrm{FeFe}_{2}-\mathrm{CN}_{1}$ $900 / \mathrm{C} \quad\left(\mathrm{N} \quad \mathrm{wt} \%=0.74, \mathrm{~T}_{\mathrm{D}} \approx 400^{\circ} \mathrm{C}\right)>\mathrm{Fe}_{2} \mathrm{Fe}-\mathrm{CN}_{\mathrm{l}} \quad 900 / \mathrm{C} \quad(\mathrm{N}$ wt $\left.\%=0.38, \mathrm{~T}_{\mathrm{D}} \approx 550^{\circ} \mathrm{C}\right)>\mathrm{XC}-72 \mathrm{R} \quad\left(\mathrm{N} \quad \mathrm{wt} \%=0, \mathrm{~T}_{\mathrm{D}} \approx 680^{\circ} \mathrm{C}\right)$. The relatively low $T_{D}$ value of the Pt/C ref. demonstrates that Pt NPs are efficient catalysts for the degradation of the carbon support [54]. The correlation existing between $T_{D}$ and $\mathbf{A}$ process (see Fig. 1(b)) highlights that the CN-based ECs include two main types of Fe species: (i) oxophilic Fe species which, thanks to their stabilization in "coordination nests" (see above), are not affected significantly by $\mathbf{A}$ and modulate $\mathrm{T}_{\mathrm{D}}$; and (ii) other "inert" Fe species, not stabilized in "coordination nests", which are easily removed during $\mathbf{A}$ and do not affect $T_{D}$. The HR-TGA profile in the hightemperature wing corresponds to the $\mathrm{Fe}_{\mathrm{x}} \mathrm{O}_{\mathrm{y}}$ residue under an oxidizing atmosphere. The wt\% of this latter residue is in accordance with the Fe assay (see Table 1 ) and in ECs rises in the order: $\mathrm{FeFe}_{2}-\mathrm{CN}_{1} 900 / \mathrm{C} \approx \mathrm{Fe}_{2} \mathrm{Fe}-\mathrm{CN}_{1} 900 / \mathrm{C}>\mathrm{FeFe}_{2}-\mathrm{CN}_{1}$ 900/ $\mathrm{C}_{\mathrm{A}}>\mathrm{Fe}_{2} \mathrm{Fe}-\mathrm{CN}_{1} 900 / \mathrm{C}_{\mathrm{A}}$.

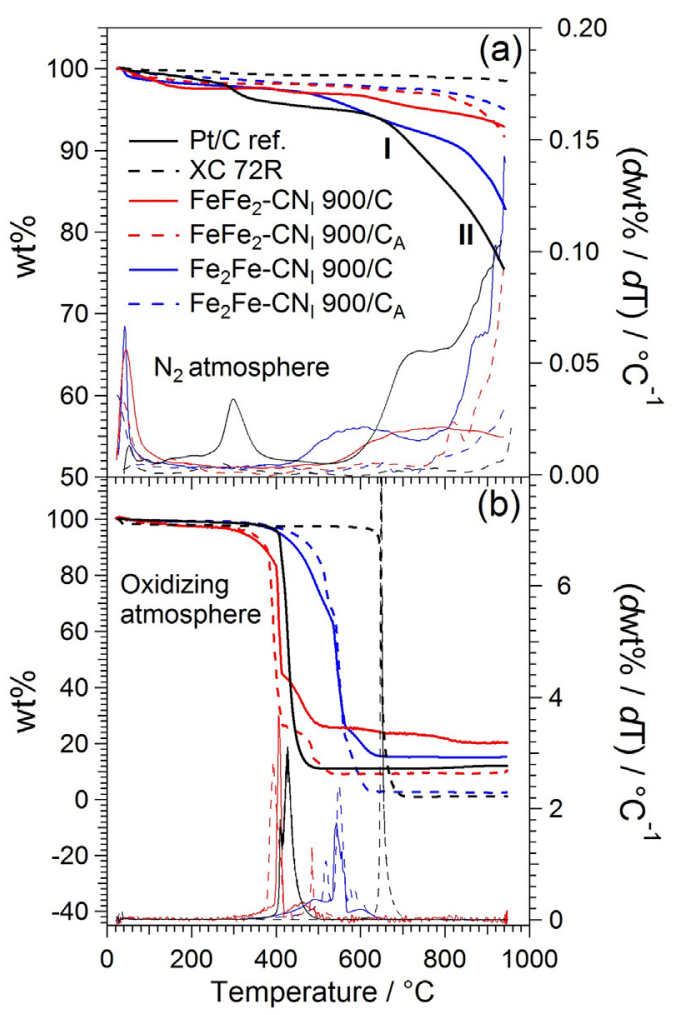

Fig. 1. HR-TGA profiles and associated derivatives of the CN-based ECs under: $\mathrm{N}_{2}$ inert atmosphere (a); and air oxidizing atmosphere (b). 


\subsection{Powder X-Ray Diffraction Studies}

The powder X-ray diffraction (XRD) profiles of the ECs shown in Fig. 2 are quantitatively analyzed by the Rietveld method in order to identify as much as possible the structural features of the different phases composing the ECs and to obtain an estimate of their domain size and relative abundance [55]. For the sake of comparison the XRD profile of XC-72R, together with the results of its Rietveld analysis, are shown in Fig. S1 of Supplementary Information.

The phase characterizing the XRD patterns of the CN-based ECs consists of a hexagonal $\mathrm{PG}_{3} / \mathrm{mc}$ component corresponding to the $\mathrm{XC}-72 \mathrm{R}$ "core" support with domain sizes in the range of $c a$. $2.2-2.5 \mathrm{~nm}, \mathrm{COD} \# 9008569$ [56]. In details, the hexagonal $\mathrm{PG}_{3} / \mathrm{mc}$ phase of $X C-72 R$ is characterized by a main $(002)$ peak at $2 \theta \approx 25^{\circ}$ and by two minor peaks at $2 \theta \approx 43^{\circ}, 56^{\circ}$ which are associated with the (111) and (004) reflections, respectively. A careful analysis of the XRD profiles of ECs demonstrates that the preparation procedure has no influence on the structure and the morphology of this phase. Peaks ascribed to Fe-based NPs are detected, which are quite sharp and correspond to metal NPs with sizes larger than $80-90 \mathrm{~nm}$. These Fe-based NPs, which are coordinated by the CN "shell" matrix, are formed during the pyrolysis process from clusters of $\mathrm{Fe}$ coordination complexes of the precursor, in accordance with the mechanism elsewhere described [38]. Briefly, the Fe-based NPs are nucleated in the precursor during the Step III of the pyrolysis (that is carried out at $900{ }^{\circ} \mathrm{C}$, see Section 2.2), and undergo a growth process which is based on a thermally-activated diffusion process [38]. The temperature of Step III is set to $900^{\circ} \mathrm{C}$ to promote the removal of heteroatoms (e.g., $\mathrm{H}, \mathrm{O}$ ), thus yielding a well-graphitized CN "shell" that ensures a facile electron transfer from the external circuit to the active metal sites [36]. Correspondingly, the well-graphitized $\mathrm{CN}$ "shell" also originates a reducing environment that is crucial in the formation of the Febased phases. Indeed, it allows the Fe(II) species of the precursor to undergo reduction, diffusion and aggregation processes which result in the formation of phases such as $\mathrm{Fe}_{3} \mathrm{C}$ (see Table 2, and below) which are mostly based on $\mathrm{Fe}(0)$. The metal component mostly consists of the following species: (a) in $\mathrm{FeFe}_{2}-\mathrm{CN}_{1} 900 / \mathrm{C}$ : cementite ( $\mathrm{Fe}_{3} \mathrm{C} ;$ S.G. Pnma; $\mathrm{a}=5.09 \AA \AA \mathrm{A}=6.75 \AA \mathrm{A} ; \mathrm{c}=4.53 \AA$; $<\mathrm{d}>>80-90 \mathrm{~nm}$; COD\#9012188 [56]) for ca. $10 \mathrm{wt} \%$; (b) in $\mathrm{Fe}_{2} \mathrm{Fe}-\mathrm{CN}_{1} 900 / \mathrm{C}$ : magnetite $\left(\mathrm{Fe}_{3} \mathrm{O}_{4}\right.$; S.G. Fd-3m; a = 8.38 $\AA$; $<\mathrm{d}>>80$ $-90 \mathrm{~nm}$; COD\#1010369 [56]) for ca. $12 \mathrm{wt} \%$, with some traces of cementite. The results above prove that nitrogen concentration in the CN "shell" plays an important role in the modulation of the structure and morphology of Fe-based species during the pyrolysis process. Indeed, as the precursor is heated to the pyrolysis temperature, it expels most of its oxygen atoms as volatile oxygenbased species such as water, $\mathrm{CO}_{2}$ and $\mathrm{CO}$ [38] which, in principle, could react with the Fe to yield the $\mathrm{Fe}_{\mathrm{x}} \mathrm{O}_{\mathrm{y}}$ derivatives. In $\mathrm{FeFe}_{2}-\mathrm{CN}_{\mathrm{l}}$ $900 / \mathrm{C}$ the relatively high $\mathrm{N}$ content in the "coordination nests" enhances the interactions between the $\mathrm{CN}$ matrix (the EC "shell") and the Fe-based NPs, thus inhibiting the formation of $\mathrm{Fe}_{\mathrm{x}} \mathrm{O}_{\mathrm{y}} \mathrm{NPs}$. In $\mathrm{Fe}_{2} \mathrm{Fe}-\mathrm{CN}_{1} 900 / \mathrm{C}$ the opposite situation is observed, demonstrating that a lower $\mathrm{N}$ content (see Table 1 ) reduces the density and strength of metal-N interactions in "coordination nests", facilitating the aggregation and growth of $\mathrm{Fe}_{\mathrm{x}} \mathrm{O}_{\mathrm{y}}$ NPs such as $\mathrm{Fe}_{3} \mathrm{O}_{4}$ (see Table 2). Furthermore, the XRD patterns indicate that $\mathbf{A}$ process influences significantly the structure of the $\mathrm{CN}$-based ECs, as follows: (1) for $\mathrm{FeFe}_{2}-\mathrm{CN}_{1} 900 / \mathrm{C}_{\mathrm{A}}$, a reduction of the overall abundance of Fe-based phases is observed; in this case, traces of

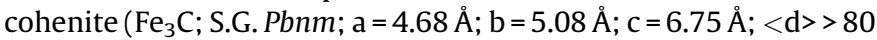
$-90 \mathrm{~nm}$; COD\#1010936 [56]), a close analogue of cementite, together with a small amount of austenite, $(\gamma$-Fe; S.G. Fm-3m; $\mathrm{a}=3.60 \AA$; $<\mathrm{d}>>80-90 \mathrm{~nm}$; COD\#9012188 [56]), are detected; (2) for $\mathrm{Fe}_{2} \mathrm{Fe}-\mathrm{CN}_{1} 900 / \mathrm{C}_{\mathrm{A}}$, no Fe-based phase is detected (see Fig. 2(d) and Table 2). It is pointed out that none of the metal phases detected in either pristine or activated CN-based ECs is expected to play a major role in their ORR performance (see below), with the possible exception of cementite (see Section 3.5). These pieces of evidence are in accordance with the chemical composition results (see Table 1), demonstrating that the interactions between the $\mathrm{CN}$ matrix (the "shell") and Fe-based species are crucial in modulating the structure and the morphology of active sites in these ECs. In details, in $\mathrm{FeFe}_{2}-\mathrm{CN}_{1} 900 / \mathrm{C}$, the strong [Fe-based NP]/[CN matrix] interactions inhibit the complete elimination of Fe-based phases

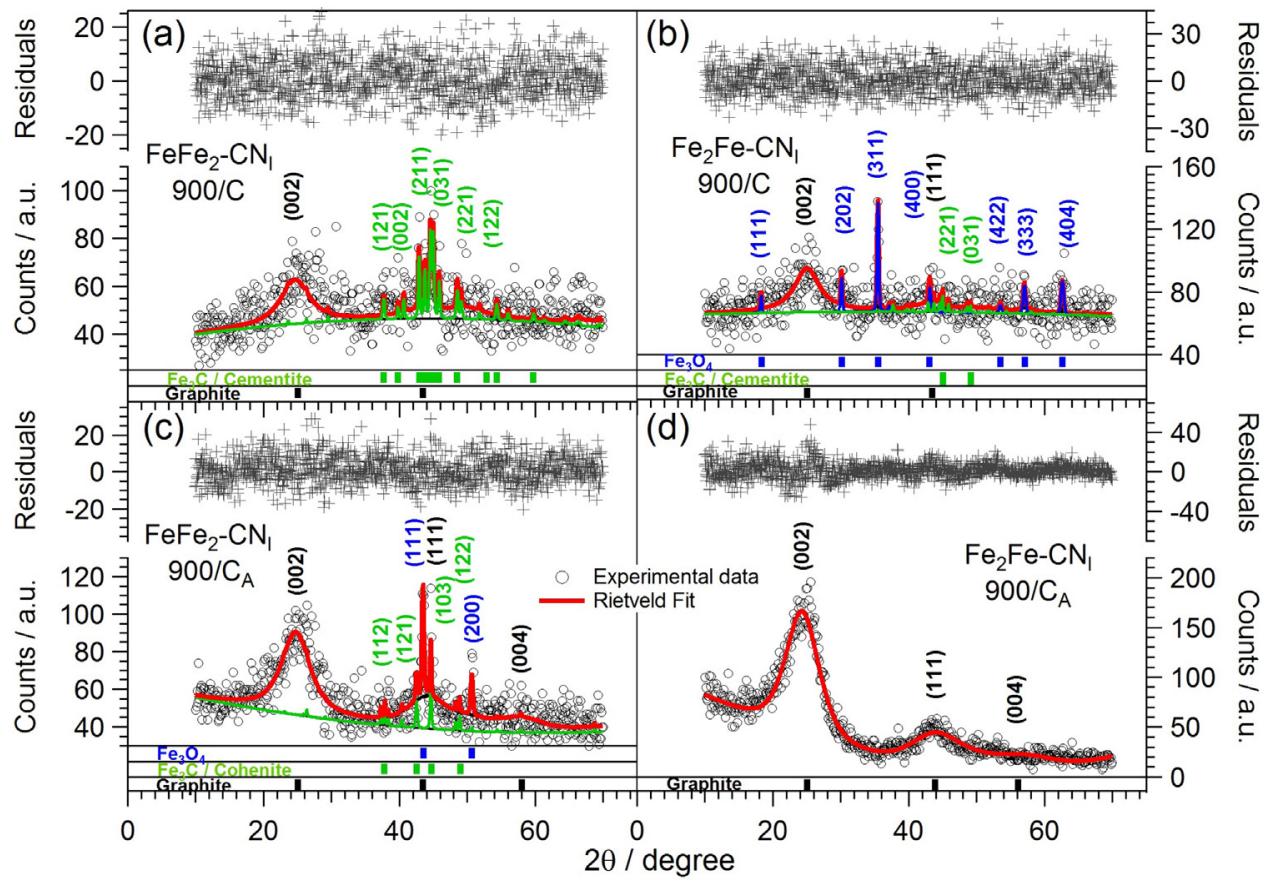

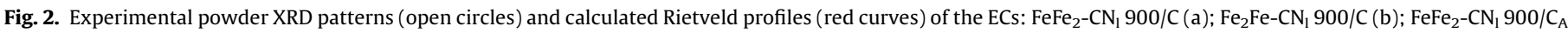
(c); and $\mathrm{Fe}_{2} \mathrm{Fe}-\mathrm{CN}_{1} 900 / \mathrm{C}_{\mathrm{A}}$ (d). 
Table 2

Results of Rietveld analysis of CN-based ECs and of XC-72R powder XRD patterns.

\begin{tabular}{|c|c|c|c|c|c|c|}
\hline Sample & Phase & Space group & Phase abundance/wt\% & Cell Parameters/Å & Particle size/nm & $R_{\mathrm{wp}}{ }^{\mathrm{a}} / \%$ \\
\hline \multirow[t]{2}{*}{$\mathrm{FeFe}_{2}-\mathrm{CN}_{l} \mathrm{900} / \mathrm{C}$} & C & Hexagonal $P 6_{3} / m c$ & 90 & $\begin{array}{l}\mathrm{a}=2.48 \\
\mathrm{c}=7.22\end{array}$ & 2.2 & 15.1 \\
\hline & Cementite $\mathrm{Fe}_{3} \mathrm{C}$ & Orthorombic Pnma & 10 & $\begin{array}{l}a=5.09 \\
b=6.75 \\
c=4.53\end{array}$ & $>80-90$ & \\
\hline \multirow[t]{3}{*}{$\mathrm{FeFe}_{2}-\mathrm{CN}_{l} 900 / C_{A}$} & C & Hexagonal $P 6_{3} / m c$ & 95 & $\begin{array}{l}\mathrm{a}=2.46 \\
\mathrm{c}=7.18\end{array}$ & 2.3 & 14.0 \\
\hline & Austenite $(\gamma$-Fe $)$ & Cubic Fm-3m & 3 & $a=3.60$ & $>80-90$ & \\
\hline & Cohenite $\mathrm{Fe}_{3} \mathrm{C}$ & Orthorombic Pbnm & 2 & $\begin{array}{l}a=4.68 \\
b=5.08 \\
c=6.75\end{array}$ & $>80-90$ & \\
\hline \multirow[t]{3}{*}{$\mathrm{Fe}_{2} \mathrm{Fe}-\mathrm{CN}_{l} 900 / \mathrm{C}$} & $\mathrm{C}$ & Hexagonal $P 6_{3} / m c$ & 85 & $\begin{array}{l}\mathrm{a}=2.52 \\
\mathrm{c}=7.10\end{array}$ & $2-3$ & 12.2 \\
\hline & Magnetite $\mathrm{Fe}_{3} \mathrm{O}_{4}$ & Cubic $F d-3 m$ & 12 & $\mathrm{a}=8.38$ & $>80-90$ & \\
\hline & Cementite $\mathrm{Fe}_{3} \mathrm{C}$ & Orthorombic Pnma & 3 & $\begin{array}{l}a=5.09 \\
b=6.74 \\
c=4.53\end{array}$ & $>80-90$ & \\
\hline $\mathrm{Fe}_{2} \mathrm{Fe}-\mathrm{CN}_{\mathrm{l}} 900 / \mathrm{C}_{A}$ & C & Hexagonal $\mathrm{PG}_{3} / \mathrm{mc}$ & 100 & $\begin{array}{l}\mathrm{a}=2.48 \\
\mathrm{c}=7.29\end{array}$ & 2.5 & 15.9 \\
\hline$X C-72 R$ & C & Hexagonal $P 6_{3} / m c$ & 100 & $\begin{array}{l}\mathrm{a}=2.48 \\
\mathrm{c}=7.32\end{array}$ & 3.4 & 16.5 \\
\hline
\end{tabular}

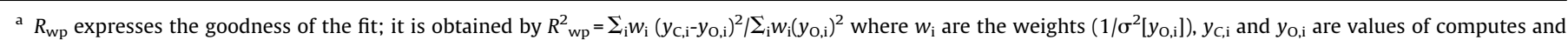
observed intensities [55].

upon A. The opposite behavior is revealed for $\mathrm{Fe}_{2} \mathrm{Fe}-\mathrm{CN}_{1} 900 / \mathrm{C}$ where, owing to the weak [Fe-based NP]/[CN matrix] interactions, no Fe-based phases are left in the ECs after $\mathbf{A}$. In particular, it is highlighted that $\mathrm{Fe}_{3} \mathrm{O}_{4}$ disappears completely upon $\mathbf{A}$ (see Table 2); nonetheless, with respect to $\mathrm{Fe}_{2} \mathrm{Fe}-\mathrm{CN}_{1} 900 / \mathrm{C}$, the ORR performance of $\mathrm{Fe}_{2} \mathrm{Fe}-\mathrm{CN}_{1} 900 / \mathrm{C}_{\mathrm{A}}$ is significantly improved (see Section 3.6). Accordingly, it can be argued that $\mathrm{Fe}_{3} \mathrm{O}_{4}$ does not play an important role in the ORR. During $\mathbf{A}$ the cementite phase detected in pristine $\mathrm{FeFe}_{2}-\mathrm{CN}_{1} 900 / \mathrm{C}$ is substituted by much smaller amounts of cohenite and austenite (see Table 2). However, with respect to $\mathrm{FeFe}_{2}-\mathrm{CN}_{1} 900 / \mathrm{C}$, the ORR performance of $\mathrm{FeFe}_{2}-\mathrm{CN}_{1}$ $900 / C_{A}$ is markedly raised (see Section 3.6). On these bases, and taking into consideration that the most highly performing ORR active sites in typical "Pt-free" Fe-N-C ECs comprise $\mathrm{C}$ and $\mathrm{N}$ atoms coordinating Fe species and not extended Fe-based phases [57], it can be assumed that in the $\mathrm{CN}$-based ECs presented in this work cementite, cohenite and austenite do not influence significantly the ORR performance, even if they could play some role to improve the selectivity towards the 4-electron mechanism (see Section 3.5, below).

\subsection{Morphology}

In SEM micrographs (see Fig. 3) of proposed ECs a dark background is visible, corresponding to the carbon-based matrix, which is dotted by bright submicrometric $(\mathrm{d}<200 \mathrm{~nm})$ spots representative of metal-rich grains. A comparison of the morphology of pristine ECs (Fig. 3(a) and Fig. 3(b)) with that of activated ECs (Fig. 3(c) and Fig. 3(d)) highlights a significant rarefaction of the bright spots. In particular, no bright grains are revealed on $\mathrm{Fe}_{2} \mathrm{Fe}-$ $\mathrm{CN}_{1} 900 / \mathrm{C}_{\mathrm{A}}$. This evidence demonstrates that $\mathbf{A}$ is a very efficient process in eliminating the Fe-based NPs in this sample (see Table 1 and Fig. 2(d)), while an insignificant amount of Fe particles (even though they are directly exposed to the HF solution) can be still surviving after the treatment $\mathbf{A}$ as previously reported by Mayrhofer and coworkers [57,58]. Fig. 4 displays the HR-TEM images of the CN-based ECs.

A careful analysis of the micrographs of Fig. 4(a) and (c) shows that the pristine $\mathrm{CN}$-based ECs consist of aggregates of "core-shell" NPs. It is to be noticed that, interestingly: (i) the XC-72R carbon black "core" NPs are uniformly covered by a foamy carbon nitride "shell" embedding the dark metal-rich nanoparticles with sizes in the range $20<\mathrm{d}<80 \mathrm{~nm}$; and (ii) A process is very efficient to disaggregate the "core-shell" nanoparticles of the ECs and eliminate Fe-based NPs from both $\mathrm{FeFe}_{2}-\mathrm{CN}_{1} 900 / \mathrm{C}_{\mathrm{A}}$ and $\mathrm{Fe}_{2} \mathrm{Fe}-\mathrm{CN}_{1} 900 / \mathrm{C}_{\mathrm{A}}$ (see Fig. 4(b) and (d)). The high-resolution TEM images of $\mathrm{FeFe}_{2}-\mathrm{CN}_{1} 900 / \mathrm{C}$ and $\mathrm{FeFe}_{2}-\mathrm{CN}_{1} 900 / \mathrm{C}_{\mathrm{A}}$ (see Fig. 5) show that $\mathbf{A}$ does not affect the morphology of the $\mathrm{CN}$ "shell" significantly.

The HR-TEM micrographs of Fig. 5 provide crucial information on the morphology of the CN "shell" matrix and on the chemical composition (see Table 1) of ECs, which corroborates and completes the structural studies carried out by powder XRD (see Section 3.3). In detail, the interplanar distances measured in the micrographs of Fig. 5 coincide with powder XRD results and prove that the following metal NPs are present: (a) for $\mathrm{FeFe}_{2}-\mathrm{CN}_{1}$ $900 / C$, systems with an interplanar distance of ca. $2.4 \AA$ (see Fig. 5(a)), corresponding to the typical $d_{121}$ values of cementite $\left(\mathrm{Fe}_{3} \mathrm{C}\right)$; (b) for $\mathrm{FeFe}_{2}-\mathrm{CN}_{1} 900 / \mathrm{C}_{\mathrm{A}}$, the revealed interplanar distance is ca. $2.1 \AA$ (see Fig. 5(b)), which is attributed to the $d_{111}$ of fcc $\gamma$-Fe (austenite). The presence of these NPs induces in both ECs ordering in the CN "shell". Indeed, well-ordered "onion-like" carbon nitride layers are formed, which encapsulate the metal NPs in "coordination nests". The CN "shell" presents the typical $\mathrm{d}_{002} \approx 3.6 \AA$ interplanar distance usually revealed in graphite-like carbon nitride structures $[38,44]$. It should be noted that upon A: (a) the thickness of the "onion-like" $\mathrm{CN}$ "shell" is reduced by $50 \%$ (from $\approx 6$ to $\approx 3 \mathrm{~nm}$ for $\mathrm{FeFe}_{2}-\mathrm{CN}_{1} 900 / \mathrm{C}$ and $\mathrm{FeFe}_{2}-\mathrm{CN}_{1} 900 / \mathrm{C}_{\mathrm{A}}$, respectively); and (b) the overall porosity of the ECs rises, as revealed by HR-TEM micrographs (see Fig. 4(a) and (b)). On these bases, an "onion-like" CN "shell" with a thickness of $\approx 6$ and $\approx 3 \mathrm{~nm}$ includes a number of "onion-like" $\mathrm{CN}$ sheets equal to $\mathrm{ca}$. 15-20 and 8-10 layers, respectively. A also acts to etch Fe species significantly (see Table 1); accordingly, the size of metal NPs is decreased (see Fig. 4(a) and (b)). However, in $\mathrm{FeFe}_{2}-\mathrm{CN}_{1} 900 / \mathrm{C}_{\mathrm{A}}$ the surface of metal NPs is still wrapped by the "onion-like" CN layers (see Fig. 5(b)). This evidence points out that the latter layers are very flexible. Indeed, they are able to shrink, matching the morphology of the underlying metal NP template.

A similar behavior of morphology is revealed for pristine $\mathrm{Fe}_{2} \mathrm{Fe}-$ $\mathrm{CN}_{1} 900 / \mathrm{C}$, where $\mathrm{Fe}_{3} \mathrm{O}_{4}$ (magnetite) NPs with an interplanar distance of $d_{131} \approx 2.5 \AA$, are covered by a CN "shell". The inspection of HR-TEM images of $\mathrm{Fe}_{2} \mathrm{Fe}-\mathrm{CN}_{1} 900 / \mathrm{C}$ and $\mathrm{Fe}{ }_{2} \mathrm{Fe}-\mathrm{CN}_{1} 900 / \mathrm{C}_{\mathrm{A}}$ shows that: (a) the structure and composition of NPs are in accordance with powder XRD studies (see Table 2); (b) a clear "core-shell" 


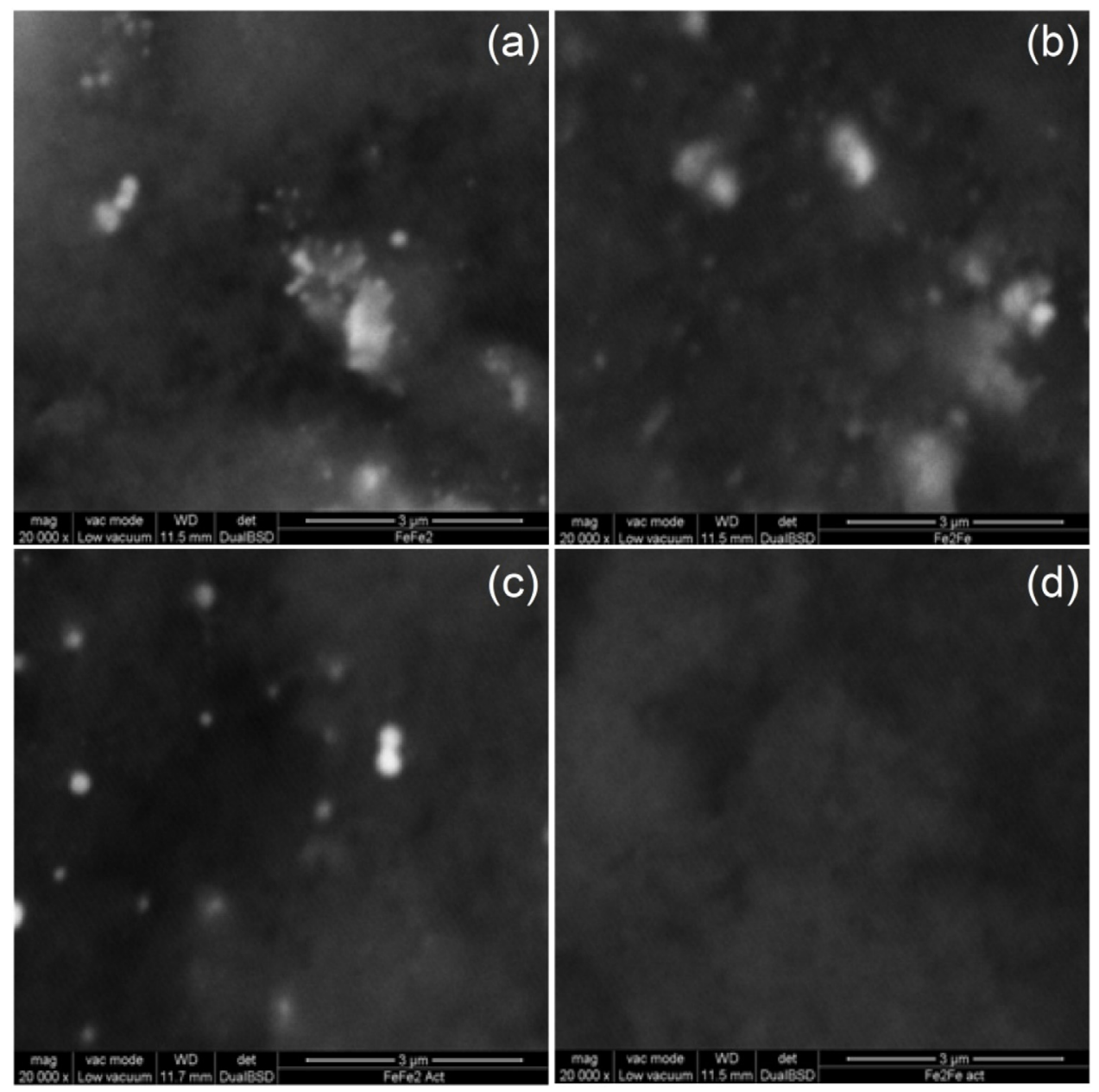

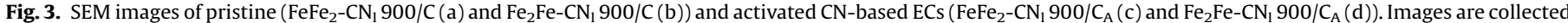
with backscattered electrons.

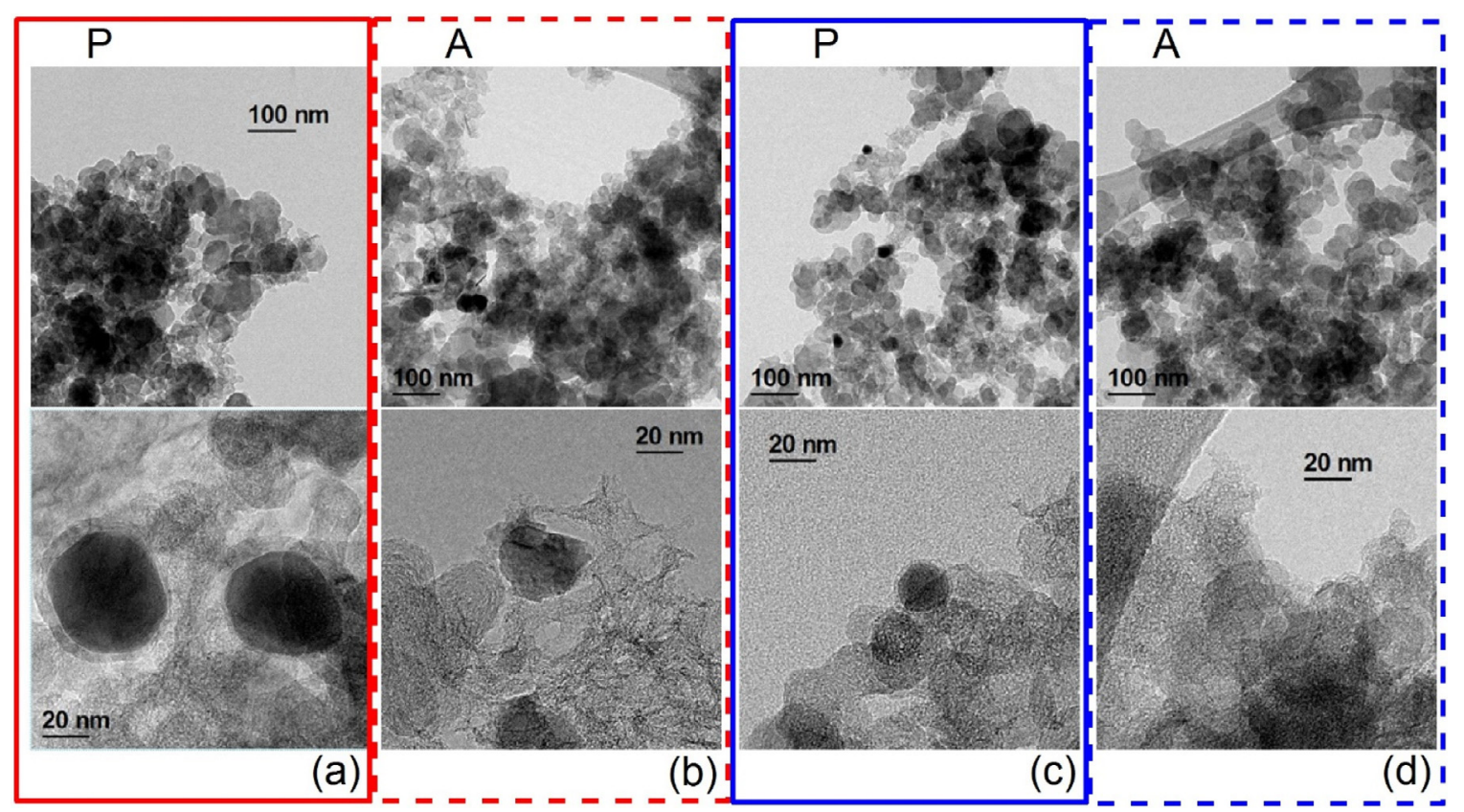

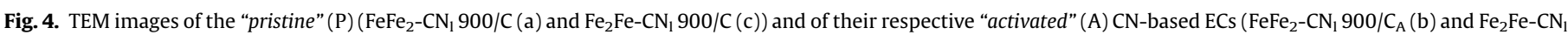
$\left.900 / C_{A}(d)\right)$. 

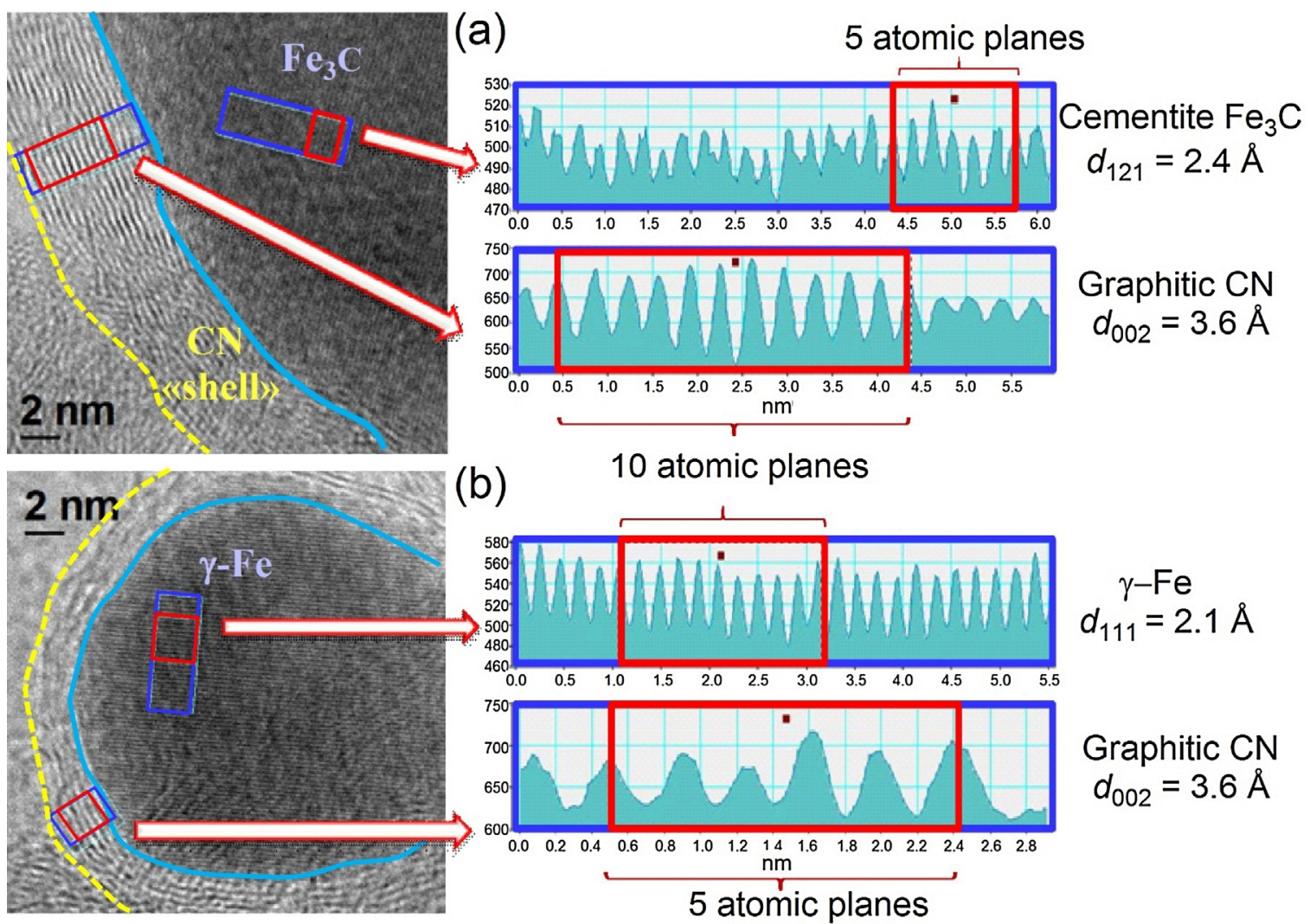

$$
\begin{gathered}
\text { Graphitic CN } \\
d_{002}=3.6 \AA
\end{gathered}
$$

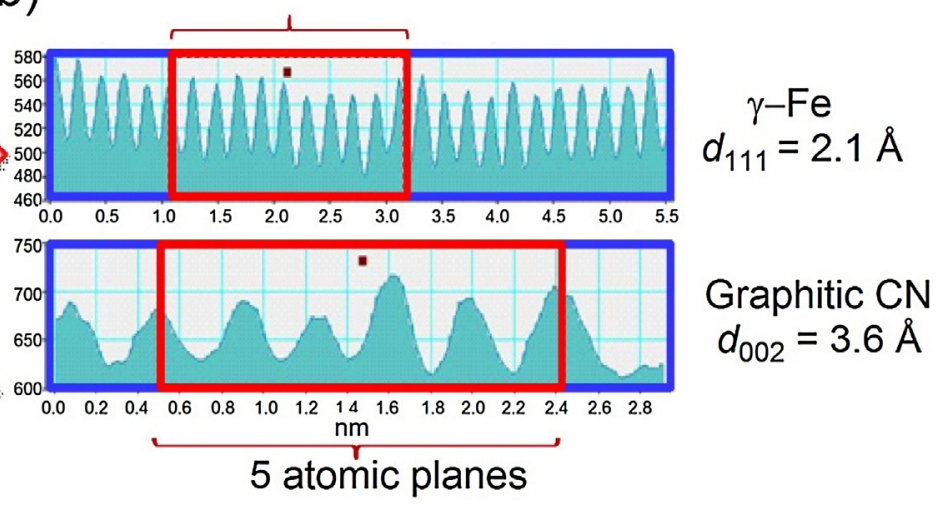

Fig. 5. HR-TEM micrographs of: "pristine" $\mathrm{FeFe}_{2}-\mathrm{CN}_{1} 900 / \mathrm{C}$ (a); and "activated" $\mathrm{FeFe}_{2}-\mathrm{CN}_{1} 900 / \mathrm{C}_{\mathrm{A}}$ electrocatalysts (b).

morphology characterizes the NPs; and (c) the CN "shell" shows a foamy morphology and wraps the XC-72R "core" NPs (see Fig. S2 of Supplementary Information).

A comparison between the results reported in Table 3 indicates that $\mathbf{A}$ raises the BET area of the ECs. It should be pointed out that in both activated $\mathrm{CN}$-based ECs, the area is relatively close to that of XC-72R support NPs. Taken all together, results allow to conclude that $\mathbf{A}$ is a very effective process: (a) for the disaggregation of the "core-shell" NPs; and (b) in the reduction of the thickness of their CN "shell". The results shown in Figs. 5 and S2 of Supplementary Information also suggest that a Fe-based NP must be wrapped by a minimum number of "onion-like" CN sheets (between ca. 15 and 20 ) to be stabilized and survive the activation process $\mathbf{A}$.

\subsection{X-ray photoelectron spectroscopy studies}

Further information on the correlation between the structure and the performance of the proposed ECs is obtained by investigating the surface chemical features of CN-based ECs and XC-72R by XPS.

Table 4 indicates that the surface concentration of $\mathrm{Fe}$ : (a) decreases in the order $\mathrm{Fe}_{2} \mathrm{Fe}-\mathrm{CN}_{1} 900 / \mathrm{C}>\mathrm{FeFe}_{2}-\mathrm{CN}_{1} 900 / \mathrm{C}$; and (b) is lower than the detection limit of the XPS technique for activated

Table 3

\begin{tabular}{|c|c|}
\hline Electrocatalyst & BET area ${ }^{a} / \mathrm{m}^{2} \mathrm{~g}^{-1}$ \\
\hline $\mathrm{FeFe}_{2}-\mathrm{CN}_{l} \mathrm{900} / \mathrm{C}$ & 82 \\
\hline $\mathrm{FeFe}_{2}-\mathrm{CN}_{l} 900 / C_{A}$ & 189 \\
\hline $\mathrm{Fe}_{2} \mathrm{Fe}-\mathrm{CN}_{1} 900 / \mathrm{C}$ & 197 \\
\hline $\mathrm{Fe}_{2} \mathrm{Fe}-\mathrm{CN}_{\mathrm{l}} 900 / \mathrm{C}_{\mathrm{A}}$ & 245 \\
\hline$X C-72 R$ & 194 \\
\hline
\end{tabular}

BET area of the $\mathrm{CN}$-based ECs as determined by nitrogen physisorption techniques.

a Determined by the Brunauer-Emmett-Teller (BET) method.
CN-based ECs. This, in accordance with the morphological and structural information previously discussed, shows that Fe-based NPs: (a) are encapsulated in compact "onion-like" CN "shells" in $\mathrm{FeFe}_{2}-\mathrm{CN}_{1} 900 / \mathrm{C}$ (see Fig. 5(a)), thus compromising their exposure to the outer surface of the CN-based "shells"; (b) in $\mathrm{Fe}_{2} \mathrm{Fe}-\mathrm{CN}_{1} 900 / \mathrm{C}$, they are embedded in a very porous and foam-like carbon nitride "shell" (see Fig. S2 in Supplementary Information), which facilitates their exposure on the external EC surface. A, as expected, is very effective in the elimination of Fe species (see Table 1, Figs. 3 and 4). Indeed, after $\mathbf{A}$ only Fe complexes strongly bound to the $\mathrm{CN}$ matrix are selectively left in the "shell", thus yielding very stable active sites stabilized by the "coordination nests". The lack of detection of these Fe complexes by XPS confirms these results. Furthermore, with respect to $\mathrm{XC}-72 \mathrm{R}$, in $\mathrm{CN}$-based ECs the concentration of $\mathrm{O}$ species is lower (see Table 4). This suggests that $\mathbf{A}$ promotes the selective elimination of $\mathrm{O}$ species, improving the graphitization of the $\mathrm{CN}$ matrix. In $\mathrm{Fe}_{2} \mathrm{Fe}-\mathrm{CN}_{1} 900 / \mathrm{C}_{\mathrm{A}} \mathrm{O}$ species are eliminated concurrently with the surface $\mathrm{Fe}_{\mathrm{x}} \mathrm{O}_{\mathrm{y}}$ inorganic species. The $\mathrm{N}$ density in the $\mathrm{CN}$ matrix increases on the amount of stoichiometric nitrogen of the reagents: $\mathrm{Fe}_{2} \mathrm{Fe}-\mathrm{CN}_{1} 900 / \mathrm{C}<\mathrm{FeFe}_{2}-\mathrm{CN}_{1} 900 / \mathrm{C}$. Both $\mathrm{FeFe}_{2}-\mathrm{CN}_{1} 900 / \mathrm{C}_{\mathrm{A}}$ and $\mathrm{Fe}_{2} \mathrm{Fe}-\mathrm{CN}_{1} 900 / \mathrm{C}_{\mathrm{A}}$ (see Section 3.3. and

Table 4

The chemical composition of the surface of CN-based ECs (at.\%) as determined by

\begin{tabular}{|c|c|c|c|c|}
\hline \multirow[t]{2}{*}{ Electrocatalyst } & \multicolumn{4}{|l|}{ at.\% } \\
\hline & $\mathrm{C}$ & 0 & $\mathrm{~N}$ & $\mathrm{Fe}$ \\
\hline $\mathrm{FeFe}_{2}-\mathrm{CN}_{l} \mathrm{900/ \textrm {C }}$ & 91.1 & 8.1 & 0.79 & 0.08 \\
\hline $\mathrm{FeFe}_{2}-\mathrm{CN}_{l} 900 / C_{A}$ & 92.7 & 6.9 & 0.37 & $-{ }^{a}$ \\
\hline $\mathrm{Fe}_{2} \mathrm{Fe}-\mathrm{CN}_{\mathrm{l}} \mathrm{900/ \textrm {C }}$ & 91.8 & 7.2 & 0.53 & 0.44 \\
\hline $\mathrm{Fe}_{2} \mathrm{Fe}-\mathrm{CN}_{\mathrm{l}} 900 / \mathrm{C}_{\mathrm{A}}$ & 96.5 & 3.0 & 0.55 & $-a^{a}$ \\
\hline$X C-72 R$ & 89.6 & 10.4 & $-a^{a}$ & $-^{\mathrm{a}}$ \\
\hline
\end{tabular}
XPS.

a This value is lower than the detection limit of the XPS instrumentation. 
Section 3.4.): (a) exhibit a very rough and porous morphology; and (b) have lost most of their Fe-rich phases. In the latter case, only bulk Fe-complexes strongly bound in N "coordination nests" of CN matrix are present which results in the absence of Fe signal in limited to the top surface XPS data.

The curve fit of the high-resolution XPS N 1s region (see Fig. 6) shows six peaks, which are assigned to the following six different $\mathrm{N}$-functionalities $[52,59,60]$ : cyano or imine $(398 \mathrm{eV})$; pyridinic $\mathrm{N}$ $(398.6 \mathrm{eV}) ; \mathrm{N}_{\mathrm{x}}-\mathrm{Fe}$ species (399.6 eV); pyrrolic $\mathrm{N}(400.7 \mathrm{eV})$; graphitic $\mathrm{N}$ with possible contribution of quaternary $\mathrm{N}$ $(401.8 \mathrm{eV})$; and oxidized nitrogen species $(403 \mathrm{eV})$. A comparison of the spectral features of these peaks reveals that after $\mathbf{A}$ : (i) the intensities of oxidized N peak (see Fig. 6) decrease, confirming that the graphitization of the CN matrix of the EC "shells" is improved; (ii) the density of $\mathrm{N}$-functionalities of pyrrolic nitrogen increased also due to increased graphitization; and (iii) the pyridinic and $\mathrm{N}$-ligand functionalities involved in the $\mathrm{N}_{\mathrm{x}}$-Fe "coordination nests", which are expected to play a crucial role in the ORR process [60,61], are only slightly affected. Taken all together, results allow us to summarize that: (a) the relative intensity of the peak ascribed to pyrrolic-like $\mathrm{N}$ functionalities increases in the order: $\mathrm{FeFe}_{2}-\mathrm{CN}_{1}$ $900 / \mathrm{C}<\mathrm{FeFe}_{2}-\mathrm{CN}_{1} 900 / \mathrm{C}_{\mathrm{A}}<\mathrm{Fe}_{2} \mathrm{Fe}-\mathrm{CN}_{1} 900 / \mathrm{C} \approx \mathrm{Fe}_{2} \mathrm{Fe}-\mathrm{CN}_{1} 900 / \mathrm{C}_{\mathrm{A}}$; and (b) the peak intensity ratio $\mathrm{N}_{\mathrm{x}}$ - $\mathrm{Fe} /$ pyrrolic $\mathrm{N}$ in $\mathrm{FeFe}_{2}-\mathrm{CN}_{1} 900 / \mathrm{C}$ and $\mathrm{FeFe}_{2}-\mathrm{CN}_{1} 900 / \mathrm{C}_{\mathrm{A}}$ is larger than the values of $\mathrm{Fe}_{2} \mathrm{Fe}-\mathrm{CN}_{1} 900 / \mathrm{C}$ and $\mathrm{Fe}_{2} \mathrm{Fe}-\mathrm{CN}_{1} 900 / \mathrm{C}_{\mathrm{A}} \mathrm{ECs}$ (see Table $\mathrm{S} 1$ ). This permits us to propose that probably: (a) pyrrolic-like $\mathrm{N}$ functionalities act to facilitate the first 2-electron reduction step of $\mathrm{O}_{2}$ into $\mathrm{H}_{2} \mathrm{O}_{2}$ [52,60,61]; and (b) $\mathrm{N}_{\mathrm{x}}$-Fe species play a crucial role in the modulation of the overall ORR kinetics in "Pt-free" ECs $[60,62]$. Now, if we consider that the density of pyrrolic $\mathrm{N}$-like functionalities and $\mathrm{N}_{\mathrm{x}}-\mathrm{Fe}$ coordination species are crucial parameters for the modulation of the ORR activity and selectivity of ECs, it is expected that the best EC in the ORR process is $\mathrm{FeFe}_{2}-\mathrm{CN}_{1} 900 / \mathrm{C}_{\mathrm{A}}$. The latter $\mathrm{EC}$ has a higher relative amount of $\mathrm{N}$ coordinated to iron with respect to pyrrolic $\mathrm{N}$, that facilitates more efficient reduction of hydrogen peroxide by $\mathrm{N}_{\mathrm{x}}-\mathrm{Fe}$ species. This sample also includes the $\mathrm{Fe}_{3} \mathrm{C}$ phase which, according to "in-situ" XAS (X-ray Absorption Spectroscopy) studies, should be inactive towards $\mathrm{O}_{2}$ adsorption; on the other hand, subsurface $\mathrm{Fe} / \mathrm{Fe}_{\mathrm{x}} \mathrm{C}$ may also act to stabilize the peroxide intermediate on the active site in the alkaline medium [63].

\subsection{CV-TF-RRDE investigations}

The "ex situ" performance of the CN-based ECs in the ORR process is investigated by CV-TF-RRDE in order to detect the kinetic

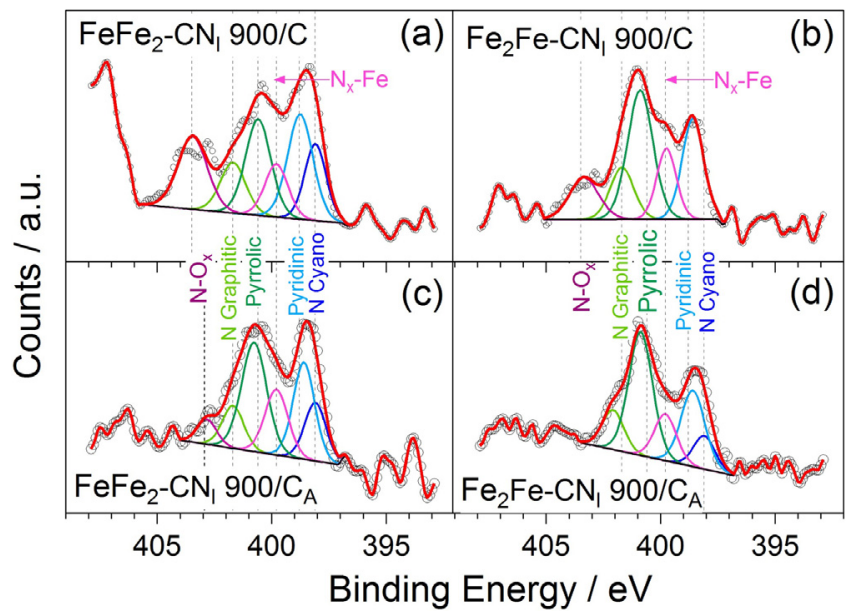

Fig. 6. High resolution $N 1 s$ XPS spectra of the CN matrix of ECs: $\mathrm{FeFe}_{2}-\mathrm{CN}_{1} 900 / \mathrm{C}$ (a), $\mathrm{Fe}_{2} \mathrm{Fe}-\mathrm{CN}_{1} 900 / \mathrm{C}$ (b), $\mathrm{FeFe}_{2}-\mathrm{CN}_{1} 900 / \mathrm{C}_{\mathrm{A}}$ (c) and $\mathrm{Fe}_{2} \mathrm{Fe}-\mathrm{CN}_{1} 900 / \mathrm{C}_{\mathrm{A}}$ (d). parameters describing the reduction mechanisms and the selectivity towards the four-electron process. The ORR disk current densities ( $\left.\mathrm{j}_{\text {ORR }}\right)$ and ring currents $\left(\mathrm{I}_{\mathrm{r}}\right)$ of both pristine and activated ECs on E vs. the reversible hydrogen electrode (RHE) are shown in Fig. 7.

The Tafel plots derived from the ORR profiles reported in Fig. 7 [44] are shown in Fig. 8.

In the acid environment the ORR Tafel slopes decrease from $c a$. $170 \mathrm{mV} \mathrm{dec}^{-1}$ to $c a .120 \mathrm{mV} \mathrm{dec}^{-1}$ upon A. In the alkaline environment, the Tafel slopes: (a) show values of $c a .70 \mathrm{mV} \mathrm{dec}^{-1}$ at low ORR overpotentials ( $\eta$ ); (b) increase on $\eta$; and (c) decrease after $\mathbf{A}$. The specific surface activity (SSA) values of the ECs in the alkaline environment is obtained by means of Eq. (1):

$S S A=\frac{i_{k}}{m_{E C} \cdot A_{B E T}}$

where $i_{k}$ is the ORR kinetic current determined on Fig. 8(b) at $0.85 \mathrm{~V}$ vs. RHE, $\mathrm{m}_{\mathrm{EC}}$ is the EC mass deposited on the RRDE tip and $A_{B E T}$ is the BET area of the ECs obtained by nitrogen physisorption technique (see Table 3). SSA results are summarized in Table 5.

The selectivity in the 4-electron pathway of the ORR is gauged by evaluating the fraction of hydrogen peroxide $\left(\mathrm{X}_{\mathrm{H}_{2} \mathrm{O}_{2}}\right)$ oxidated at the ring by means of Eq. (2) [49]:

$X_{\mathrm{H}_{2} \mathrm{O}_{2}}=\frac{\frac{2 I_{\mathrm{r}}}{N}}{I_{\mathrm{D}}+\frac{I_{\mathrm{r}}}{N}}$

where $I_{D}$ and $I_{r}$ are the current values measured concurrently on the glassy-carbon disk and on the platinum ring. The collection efficiency of the ring is $\mathrm{N}=0.38 . X_{\mathrm{H}_{2} \mathrm{O}_{2}}$ results on $\mathrm{E}$ are plotted in Fig. 9.

The selectivity in the 4-electron pathway of the ECs: (a) is significantly lower than that of the Pt/C ref.; (b) increases after $\mathbf{A}$ in the acid solution; and (c) shows the opposite trend of the acid
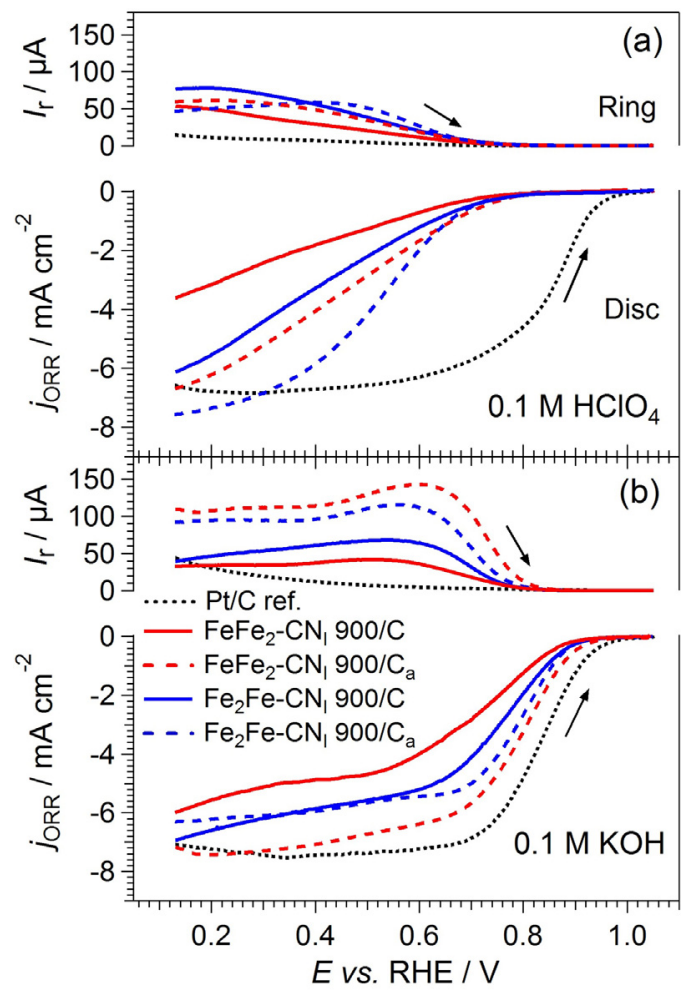

Fig. 7. ORR profiles of the $\mathrm{CN}$-based ECs and of the $\mathrm{Pt} / \mathrm{C}$ ref. in an $\mathrm{O}_{2}$ atmosphere. The cell is filled with: $0.1 \mathrm{M} \mathrm{HClO}_{4}$ (a); and $0.1 \mathrm{M} \mathrm{KOH} \mathrm{(b).} \mathrm{T}=298 \mathrm{~K}$, sweep rate $=20 \mathrm{mV} \mathrm{s}^{-1}$, electrode rotation rate $1600 \mathrm{rpm}, \mathrm{PO}_{2}=1 \mathrm{~atm}$. 


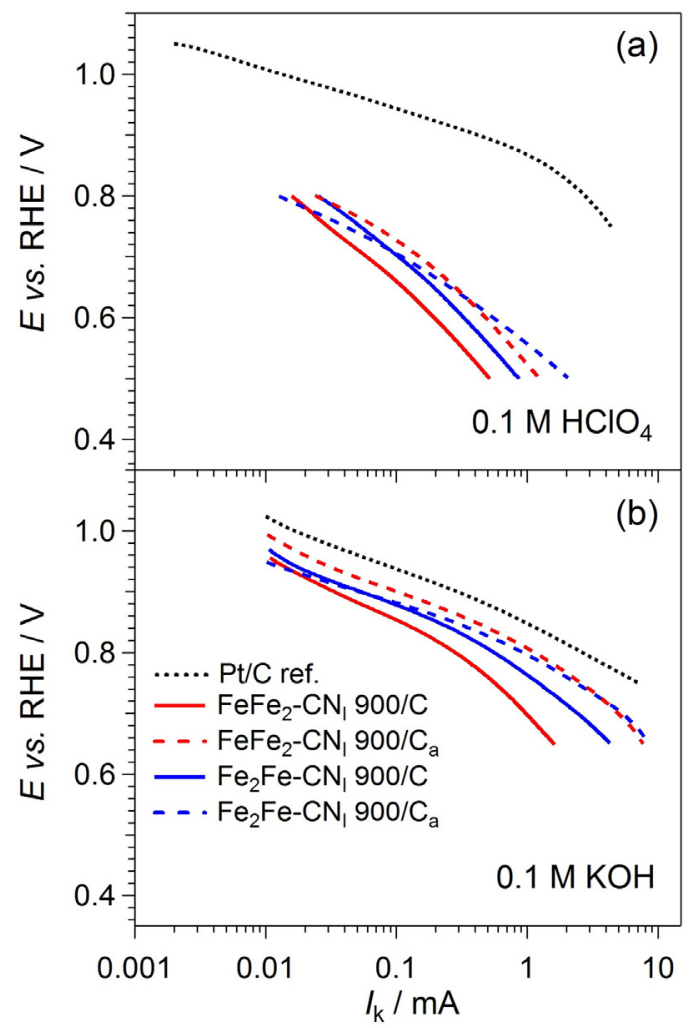

Fig. 8. ORR Tafel plots of data shown in Fig. 7. Cell filled with: $0.1 \mathrm{M} \mathrm{HClO}_{4}$ (a) and $0.1 \mathrm{M} \mathrm{KOH} \mathrm{(b).} \mathrm{The} \mathrm{experimental} \mathrm{conditions} \mathrm{are} \mathrm{reported} \mathrm{in} \mathrm{the} \mathrm{caption} \mathrm{of} \mathrm{Fig.} 7$.

solution in the alkaline environment. A quantitative comparison of the ORR performance of the proposed ECs is carried out evaluating the following figures of merit: (a) $E\left(\mathrm{j}_{5 \%}\right)$, the "onset potential"; and (b) $X^{*}{ }_{\mathrm{H}_{2} \mathrm{O}_{2}}$, the "ORR selectivity at $0.3 \mathrm{~V}$ vs. RHE". $E\left(\mathrm{j}_{5 \%}\right)$ is the electrode potential corresponding to an ORR current density equal to $5 \%$ of the maximum ORR limiting current determined for the Pt/C ref. at ca. $0.3 \mathrm{~V}$ vs. RHE in the same conditions. $X_{\mathrm{H}_{2} \mathrm{O}_{2}}$ is obtained by Eq. (2) and the data of Fig. 7 at a potential of $0.3 \mathrm{~V} v s$. RHE.

Results (see Figs. 7-10 and Table 5) show that in the acid environment $E\left(\mathrm{j}_{5 \%}\right)$ values of the ECs are $c a .220 \mathrm{mV}$ higher than that of $\mathrm{Pt} / \mathrm{C}$ ref. Taking all together, this demonstrates that, in the alkaline environment, the overall ORR performance of the CN-based ECs is significantly improved (see Fig. 7) and approaches that of the $\mathrm{Pt} / \mathrm{C}$ ref. This behavior can be rationalized considering that: (a) in the acid environment, the ORR occurs when $\mathrm{O}_{2}$ is adsorbed on the "inner-sphere" of EC NPs [64] which, for the Pt/C ref., yields strong $\mathrm{Pt}-\mathrm{O}_{2, \mathrm{ad}}{ }^{-}$and $\mathrm{Pt}-\mathrm{O}_{\mathrm{ad}}$ coordination bonds [65]; while (b) in the alkaline solutions, in accordance with other studies [64], the ORR takes place involving two concurring $\mathrm{O}_{2}$ adsorption phenomena on the metal active sites. In this latter case, the two processes consist of: (i) a first one, similar to that occurring in acid

Table 5

SSA of the CN-based ECs in the alkaline environment.

\begin{tabular}{ll}
\hline Electrocatalyst & $\mathrm{SSA} / \mu \mathrm{Acm}^{-2}$ \\
\hline $\mathrm{FeFe}_{\mathbf{2}}-\mathrm{CN}_{\boldsymbol{l}} \mathbf{9 0 0 / C}$ & 0.87 \\
$\mathrm{FeFe}_{\mathbf{2}}-\mathrm{CN}_{\boldsymbol{l}} \mathbf{9 0 0 / C _ { \boldsymbol { A } }}$ & 1.41 \\
$\mathrm{Fe}_{\boldsymbol{2}} \mathbf{F e}-\mathrm{CN}_{\boldsymbol{l}} \mathbf{9 0 0 / C}$ & 0.70 \\
$\mathrm{Fe}_{2} \mathbf{F e}-\mathrm{CN}_{\boldsymbol{l}} \mathbf{9 0 0 / C _ { \boldsymbol { A } }}$ & 0.74 \\
$\mathbf{P t} / \boldsymbol{C}$ ref. & $473^{\mathrm{a}}$ \\
\hline
\end{tabular}

a This value refers only to the Pt nanocrystals supported on the $\mathrm{Pt} / \mathrm{C}$ ref; the loading of Pt on the RRDE tip is $15 \mu \mathrm{g} \mathrm{cm}^{-2}$, the Pt specific surface area, as determined by CO stripping, is equal to $68 \mathrm{~m}^{2} \mathrm{gPt}^{-}$.

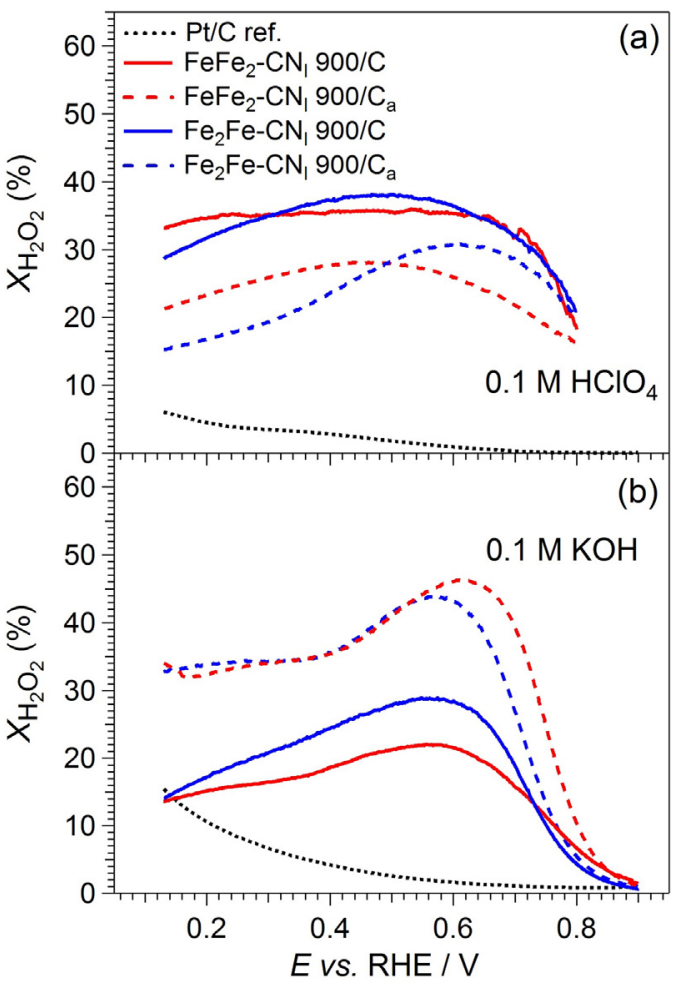

Fig. 9. ORR selectivity profiles of the $\mathrm{CN}$-based ECs and of the $\mathrm{Pt} / \mathrm{C}$ ref. in a pure $\mathrm{O}_{2}$ atmosphere. The experimental conditions are shown in the caption of Fig. 7. Cell filled with $0.1 \mathrm{M} \mathrm{HClO}_{4}$ (a) and $0.1 \mathrm{M} \mathrm{KOH} \mathrm{(b).}$

solutions $(\alpha)$; and (ii) a second one, ascribed to a weaker "outersphere" $\mathrm{O}_{2}$ adsorption event $(\beta)$. ( $\beta$ ), which is less modulated by the type of the active site, occurs quite easily even in the absence of
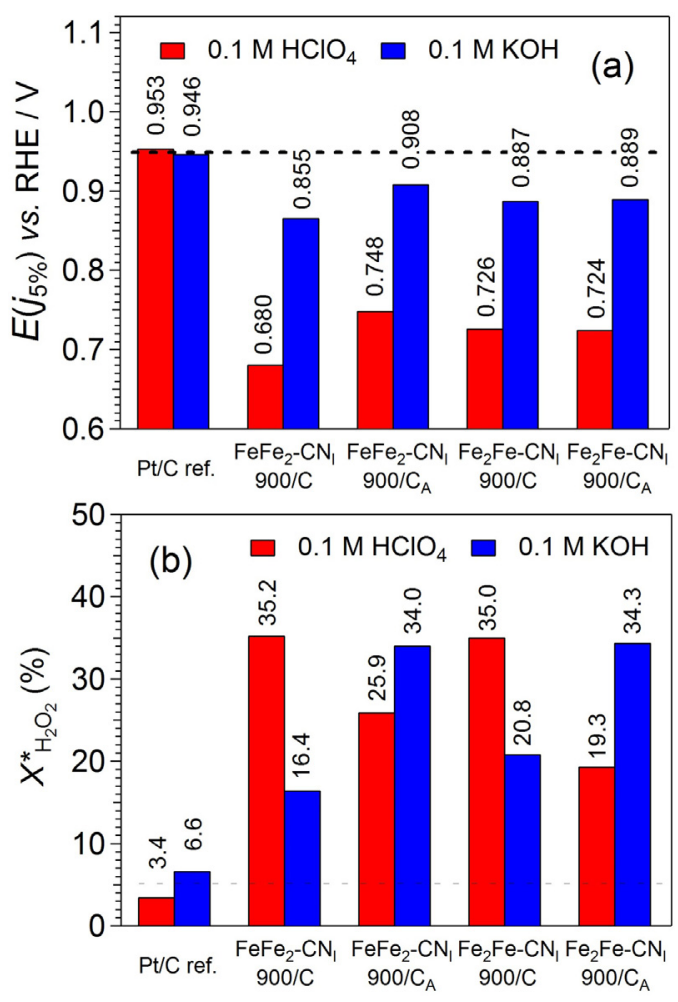

Fig. 10. Figures of merit for the performance of the $\mathrm{CN}$-based ECs. Onset potential, $E$ $\left(\mathrm{j}_{5 \%}\right)(\mathrm{a})$; ORR selectivity $\left(\mathrm{X}_{\mathrm{H}_{2} \mathrm{O}_{2}}\right)$ at $0.3 \mathrm{~V}$ vs. RHE (b). 
active sites based on platinum-group metals (PGMs) [64]. In the alkaline environment, it is expected that for the Pt/C ref. both $(\alpha)$ and $(\beta)$ processes are operating simultaneously, while in $\mathrm{CN}$-based ECs $(\alpha)$ is inhibited and at low $\eta$ the ORR proceeds mostly through $(\beta)$ process. Now, if we admit that $(\beta)$ is almost independent of the type of specific adsorption site, it is reasonable to assume that the reactivity of the entire surface of the $\mathrm{CN}$-based ECs is playing a crucial role in the ORR process. A different behavior is detected in acid solutions where the ORR process, which is modulated by the "inner-shell" $\mathrm{O}_{2}$ adsorption phenomena, occurs on the surface of the active metal sites. On this basis, SSA (see Eq. (1) and Table 5) is a meaningful figure of merit to diagnose in the kinetic regime the performance of the CN-based ECs in alkaline solution. In detail, the SSA of the CN-based ECs is almost three orders of magnitude lower than that of the $\mathrm{Pt} / \mathrm{C}$ ref. (see Table 5 ). Accordingly, with respect to $(\beta)$ process, which occurs for both the $\mathrm{Pt} / \mathrm{C}$ ref. and the $\mathrm{CN}$-based ECs, $(\alpha)$ process, which takes place at low ORR overpotentials on the Pt sites of the Pt/C ref., is responsible for the main contribution to the significantly improved ORR kinetics in this case. Finally, at $\mathrm{pH}>12$, $(\beta)$ yields a 2-electron exchange process, which produces an $\mathrm{HO}_{2}{ }^{-}$intermediate [66]. $\mathrm{HO}_{2}{ }^{-}$is reduced to water on the electrocatalyst surface, either: (i) on the same active site, or (ii) upon diffusion to another active metal site yielding a consecutive "series" of $2 \mathrm{e}^{-} \times 2 \mathrm{e}^{-}$processes with an overall $4 \mathrm{e}^{-}$pathway [64]. Due to plurality of chemical species present, mixed mechanism of ORR usually is present in "PGM-free" electrocatalysts, as different types of chemical species may facilitate either partial (first and/or second step, each involving the exchange of 2 electrons) and/or full reduction of oxygen to water (involving the exchange of 4 electrons).

Pristine $\mathrm{FeFe}_{2}-\mathrm{CN}_{1} 900 / \mathrm{C}$ shows the highest ORR $\eta$, both in the acid and in the alkaline environment (see Figs. 7 and 8). This result is consistent with a significant aggregation of the EC nanoparticles, yielding the lowest overall BET area (see Table 3) where the ORR can take place. In the acid environment the Tafel slope of pristine $\mathrm{FeFe}_{2}-\mathrm{CN}_{1} 900 / \mathrm{C}$ is very high, $\mathrm{ca} .170 \mathrm{mV} \mathrm{dec}^{-1}$; this value is determined at a relatively low ORR kinetic current of $c a .0 .1 \mathrm{~mA}$ (see Fig. 8). This Tafel slope value is associated with a very low intrinsic ORR kinetics [52]. Indeed, regardless of the expected ORR mechanism, in the low-current kinetic regime it is possible to detect a Tafel slope larger than $120 \mathrm{mV} \mathrm{dec}^{-1}$ at room temperature only if some kind of barrier is present that slows down the reaction, e.g., owing to mass-transport phenomena [67]. One possibility could be the presence of contaminants (e.g., carbon- and nitrogenbased byproducts of the pyrolysis process) that clog the ORR active sites and inhibit the adsorption of $\mathrm{O}_{2}$. In the alkaline environment, the Tafel slope of pristine $\mathrm{FeFe}_{2}-\mathrm{CN}_{1} 900 / \mathrm{C}$ : (i) at low ORR $\eta$ is equal to $\mathrm{ca} .80 \mathrm{mV} \mathrm{dec}^{-1}$; and (ii) increases up to more than $150 \mathrm{mV} \mathrm{dec}^{-1}$ as the ORR $\eta$ is raised. This evidence is interpreted assuming that in the alkaline environment the ORR takes place following the same reaction mechanism both at low and at high $\eta$; in both instances, the rate-determining step is the first electron transfer from the active site to $\mathrm{O}_{2}$, which has undergone an "outer-sphere" adsorption to the EC surface [68]. The observed change in Tafel slopes is attributed to a progressive change of the adsorption isotherm of $\mathrm{O}_{2}$ on the EC surface as $\eta$ is raised [68]. In the alkaline environment, if the $\mathrm{O}_{2}$ adsorption takes place in accordance with the Temkin and Langmuir isotherms, the Tafel slope is equal to 60 and $120 \mathrm{mV}$ $\mathrm{dec}^{-1}$, respectively [68]. On these bases, at low $\eta$ in the proposed ECs the adsorption of $\mathrm{O}_{2}$ likely takes place in accordance with an isotherm exhibiting features that fall between the extremes represented by the Temkin and Langmuir isotherms, yielding a Tafel slope value of $c a$. $80 \mathrm{mV} \mathrm{dec}^{-1}$. As $\eta$ is raised, the electron density on the electrode increases. Accordingly, the electron transfer to adsorbed $\mathrm{O}_{2}$ is facilitated and its surface coverage is lowered. In these conditions, $\mathrm{O}_{2}$ adsorption occurs more and more in accordance with a purely Langmuir isotherm, and the Tafel slope rises to $120 \mathrm{mV} \mathrm{dec}^{-1}$. At the highest $\eta$, the $I_{\mathrm{k}}$ associated to the ORR becomes so large $\left(I_{\mathrm{k}}>>1 \mathrm{~mA}\right.$, see Fig. $\left.8(\mathrm{~b})\right)$ that $\mathrm{O}_{2}$ concentration losses become an important issue, introducing a "barrier" that raises the Tafel slope to the observed value of more than $150 \mathrm{mV} \mathrm{dec}^{-1}$ [67]. In the alkaline solutions, $X_{\mathrm{H}_{2} \mathrm{O}_{2}}$ of pristine $\mathrm{FeFe}_{2}-\mathrm{CN}_{1} 900 / \mathrm{C}$ is the lowest (16.4\%), since the aggregation of the $\mathrm{CN}$-based EC NPs inhibits the elimination of the $\mathrm{HO}_{2}{ }^{-}$intermediate from the electrode layer thus reducing its detection on the ring electrode $[69,70]$. On the contrary, in the acid environment, $X^{*}{ }_{\mathrm{H}_{2} \mathrm{O}_{2}}$ of pristine $\mathrm{FeFe}_{2}-\mathrm{CN}_{1} 900 / \mathrm{C}$ is very high (ca. 35\%), suggesting that its surface is very rich in oxygen-based species (see Table 4). Therefore, the dissociative adsorption of $\mathrm{O}_{2}$ in "inner sphere" processes, which requires the presence of at least two adjacent free active sites [49,71], is hindered. Upon A, the ORR performance of $\mathrm{FeFe}_{2}-\mathrm{CN}_{1} 900 / \mathrm{C}$ is significantly improved both in the acid and in the alkaline solutions (see Fig. 7). This behavior is attributed to the ability of $\mathbf{A}$ to disaggregate the NPs of the ECs, raising both the BET area (see Table 3 ) and the number of ORR active sites. In the alkaline environment, on the basis of the SSA increase upon $\mathbf{A}$ (see Table 5) we can also assume that the turnover frequency of the active sites has been increased. Indeed, in this case, an efficient stabilization of the $\mathrm{HO}_{2}{ }^{-}$ORR intermediate is expected due to the presence of active metal sites with a high concentration of cationic Fe coordination species, which are formed when carbon and nitrogen heteroatom-based ligands are present on the $\mathrm{CN}$ matrix (the "coordination nests") [64]. In the alkaline environment, $\mathbf{A}$ improves the kinetics of the ORR processes and reduces $\eta$ : $E\left(\mathrm{j}_{5 \%}\right)$ increases from 0.855 to $0.908 \mathrm{~V}$ vs. RHE. Consequently, the contribution of $\mathrm{O}_{2}$ adsorption process following the Temkin isotherm is increased, and the Tafel slopes are concurrently reduced (see Fig. 8) [68]. In typical ORR studies, the Tafel slope progressively rises over the theoretical value of $120 \mathrm{mV} \mathrm{dec}^{-1}$ associated to a purely Langmuir adsorption isotherm as $I_{\mathrm{k}}$ is increased [46]. This phenomenon is also revealed in ORR studies carried out on a thin electrode layer such as that including the Pt/C ref. (see Section 2.4. and Fig. 8(b)). It is also highlighted that, in the alkaline medium, the Tafel slope of activated ECs is very similar to that of the Pt/C ref. (see Fig. 8(b)). The thickness of the electrode layers comprising the Pt/C ref. and the activated ECs is ca. 0.65 and $7 \mu \mathrm{m}$, respectively (see Section 2.4.). On these bases, it is concluded that the thickness itself of the electrode layer is not expected to play a major role in the ORR mechanism in this regime $(\mathrm{E}>0.7 \mathrm{~V} v \mathrm{~s}$. RHE). On the other hand, the observed disaggregation of the NPs of the ECs upon $\mathbf{A}$ allows a more facile access of the reactants to the ORR active sites in electrode layers of the same thickness, reducing the concentration losses. It is mainly this latter phenomenon provides an additional contribution in the reduction of the Tafel slope values. After $\mathbf{A}$, in the acid solutions: (a) the ORR overpotentials of ECs are very significant $\left(E\left(\mathrm{j}_{5 \%}\right)<750 \mathrm{mV} v s\right.$. RHE); and (b) the Tafel slopes decrease, reaching the value of $c a$. $120 \mathrm{mV} \mathrm{dec}^{-1}$. These results suggest that $\mathbf{A}$ removes the barriers that inhibit the ORR kinetics in the pristine ECs; most likely, the contaminants clogging the ORR active sites are removed. As a result, no $\mathrm{O}_{2}$-based intermediates are adsorbed on the surface of the active sites, as expected on the basis of a Langmuir-like isotherm with a Tafel slope equal to $c a .120 \mathrm{mV} \mathrm{dec}^{-1}$. The elimination of $\mathrm{O}$-based species from the active sites facilitates the dissociative adsorption of $\mathrm{O}_{2}$, reducing $X_{\mathrm{H}_{2} \mathrm{O}_{2}}$ in the acid environment from 35.2\% for $\mathrm{FeFe}_{2}-\mathrm{CN}_{1} 900 / \mathrm{C}$ to $25.9 \%$ for $\mathrm{FeFe}_{2}-\mathrm{CN}_{1}$ $900 / C_{A}$ (see Figs. 9 and 10). In the alkaline solution, after $\mathbf{A}$ the disaggregation of the EC NPs facilitates the elimination of the $\mathrm{HO}_{2}$ intermediates from the active site surface. The intermediates then form $\mathrm{H}_{2} \mathrm{O}_{2}$, which is easily detected at the ring electrode. The latter reveals that $X_{\mathrm{H}_{2} \mathrm{O}_{2}}^{*}$ increases from $16.4 \%$ for $\mathrm{FeFe}_{2}-\mathrm{CN}_{1} 900 / \mathrm{C}$ to 
34.0\% for $\mathrm{FeFe}_{2}-\mathrm{CN}_{1} 900 / \mathrm{C}_{\mathrm{A}}$ (see Figs. 9 and 10). "Onion-like" $\mathrm{CN}$ sheets (see Section 3.4) are expected to hinder the migration of $\mathrm{O}_{2}$ to the ORR active sites; indeed, in the case of $\mathrm{FeFe}_{2}-\mathrm{CN}_{1} 900 / \mathrm{C}$ relatively low diffusion-limited ORR currents are revealed ( $\mathrm{ca} .5$ $\mathrm{mA} \cdot \mathrm{cm}^{-2}$, see Fig. 7). Upon $\mathbf{A}$, the number of "onion-like" $\mathrm{CN}$ sheets decreases from ca. 15-20 to ca. 8-10 (see Section 3.4). Accordingly, the diffusion-limited current of the corresponding $\mathrm{FeFe}_{2}-\mathrm{CN}_{1} 900 /$ $\mathrm{C}_{\mathrm{A}}$ is raised to $\mathrm{ca} .7 .5 \mathrm{~mA} \cdot \mathrm{cm}^{-2}$ (see Fig. 7).

A comparison of the ORR profiles (see Fig. 7) shows that the ORR performance improves in the order $\mathrm{FeFe}_{2}-\mathrm{CN}_{1} 900 / \mathrm{C}<\mathrm{Fe}_{2} \mathrm{Fe}-\mathrm{CN}_{1}$ $900 / \mathrm{C}$. It is observed that for $\mathrm{Fe}_{2} \mathrm{Fe}-\mathrm{CN}_{1} 900 / \mathrm{C}$ : (i) in the alkaline environment, $E\left(\mathrm{j}_{5 \%}\right)>c a$. $30 \mathrm{mV}(0.887$ and $0.855 \mathrm{mV} v s$. RHE for $\mathrm{Fe}_{2} \mathrm{Fe}-\mathrm{CN}_{1} 900 / \mathrm{C}$ and $\mathrm{FeFe}_{2}-\mathrm{CN}_{1} 900 / \mathrm{C}$, respectively); and (ii) in the acid environment, jorR $>c a .50 \%$ at $\mathrm{V}<0.6 \mathrm{~V} v$ s. RHE (see Fig. 7(a)). Similar Tafel slopes suggest that the ORR mechanism in pristine $\mathrm{FeFe}_{2}-\mathrm{CN}_{1} 900 / \mathrm{C}$ and $\mathrm{Fe}_{2} \mathrm{Fe}-\mathrm{CN}_{1} 900 / \mathrm{C}$ is quite similar to one another for both the acid and the alkaline condition (see Fig. 8). The improved ORR performance of pristine $\mathrm{Fe}_{2} \mathrm{Fe}-\mathrm{CN}_{1} 900 / \mathrm{C}$ over $\mathrm{FeFe}_{2}-\mathrm{CN}_{1} 900 / \mathrm{C}$ can be attributed to the much larger BET area of $\mathrm{Fe}_{2} \mathrm{Fe}-\mathrm{CN}_{1} 900 / \mathrm{C}$ (see Table 3), which comprises a much higher number of active sites. This interpretation is further supported by the analysis of $X_{\mathrm{H}_{2} \mathrm{O}_{2}}$ values which, in alkaline solutions, are higher for $\mathrm{Fe}_{2} \mathrm{Fe}-\mathrm{CN}_{1} 900 / \mathrm{C}$ than for $\mathrm{FeFe}_{2}-\mathrm{CN}_{1} 900 / \mathrm{C}$ (20.8\% vs. $16.4 \%$, respectively, see Fig. 10). Indeed, as the BET area of ECs is increased, the $\mathrm{OH}_{2}{ }^{-}$intermediates are better eliminated from the electrode layer and easily detected at the RRDE ring. On the other hand, with respect to $\mathrm{FeFe}_{2}-\mathrm{CN}_{1} 900 / \mathrm{C}$, the SSA of $\mathrm{Fe}_{2} \mathrm{Fe}-\mathrm{CN}_{1} 900 / \mathrm{C}$ in the alkaline environment is slightly lower (see Table 5 ). This result is rationalized considering that, with respect to $\mathrm{FeFe}_{2}-\mathrm{CN}_{1} 900 / \mathrm{C}$, the surface concentration of cationic Fe-species bound by the carbon and nitrogen-based functionalities of the "coordination nests" is lower in $\mathrm{Fe}_{2} \mathrm{Fe}-\mathrm{CN}_{1} 900 / \mathrm{C}$ (see Section 3.5). Accordingly, the longrange electrostatic stabilization of the $\mathrm{HO}_{2}{ }^{-}$ORR intermediates is inferior, thus hindering $\mathrm{O}_{2}$ adsorption by means of "outer-shell" processes and consequently slowing the overall ORR kinetics.

A significantly improves the ORR performance of $\mathrm{Fe}_{2} \mathrm{Fe}-\mathrm{CN}_{1}$ $900 / C_{A}$. Indeed, jorR of $\mathrm{Fe}_{2} \mathrm{Fe}-\mathrm{CN}_{1} 900 / \mathrm{C}_{\mathrm{A}}$ in the mixed kineticdiffusion region is larger by $\mathrm{ca}$. $80 \%$ and $30 \%$ in the acid and alkaline environments, respectively (see Fig. 7). This is likely associated to an increase of the BET area (see Table 3), which originates ECs with a significantly increased number of ORR active metal sites. This interpretation is further supported by the growth of $X_{\mathrm{H}_{2} \mathrm{O}_{2}}^{*}$ values in the alkaline environment from $20.8 \%$ to $34.3 \%$ for $\mathrm{Fe}_{2} \mathrm{Fe}-\mathrm{CN}_{1}$ $900 / \mathrm{C}$ and $\mathrm{Fe}_{2} \mathrm{Fe}-\mathrm{CN}_{1} 900 / \mathrm{C}_{\mathrm{A}}$, respectively (see Fig. 10). Thus, a higher BET area facilitates the elimination of the $\mathrm{HO}_{2}{ }^{-}$ORR intermediates, which are then detected at the RRDE ring. In the acid environment, after $\mathbf{A}, X^{*} \mathrm{H}_{2} \mathrm{O}_{2}$ of $\mathrm{Fe}_{2} \mathrm{Fe}-\mathrm{CN}_{1} 900 / \mathrm{C}$ decreases from $35.0 \%$ to $19.3 \%$, concurrently with the reduction of the surface density of O-based functionalities (see Table 4). These latter, as expected, hinder the dissociative adsorption of $\mathrm{O}_{2}$. Finally, Table 5 shows that the SSA of $\mathrm{Fe}_{2} \mathrm{Fe}-\mathrm{CN}_{1}$ 900/C does not change significantly upon A. This demonstrates that, after A, no effects are detected on the functional features responsible for the ORR process in $\mathrm{Fe}_{2} \mathrm{Fe}-\mathrm{CN}_{1} 900 / \mathrm{C}$. These features include the surface density of active cationic Fe complexes bound in the "coordination nests" of the $\mathrm{CN}$ matrix.

\section{Conclusions}

A very reliable protocol is proposed to obtain two groups of "core-shell" ORR CN-based ECs without PGMs. The "cores" consist of XC-72R carbon black NPs, which are covered by a thin carbon nitride "shell" that embeds Fe species bound into the matrix through nitrogen and carbon-based "coordination nests". In pristine $\mathrm{ECs}$, the $\mathrm{N}$ wt\% rises in the order $\mathrm{Fe}_{2} \mathrm{Fe}-\mathrm{CN}_{1} 900 / \mathrm{C}<\mathrm{FeFe}_{2}-\mathrm{CN}_{1}$
$900 / C$. The reverse trend is observed for the thermal stability in an oxidizing atmosphere, which decreases as the capability of Fe species in active sites to promote the adsorption of $\mathrm{O}_{2}$ is raised. HR-TEM shows that in $\mathrm{FeFe}_{2}-\mathrm{CN}_{1} 900 / \mathrm{C}, \mathrm{Fe}_{3} \mathrm{C}$ nanoparticles are encapsulated in well-ordered "onion-like" carbon nitride based "coordination nests". A strongly affects the physicochemical properties of the ECs, yielding: (a) a significant increase in the degree of graphitization of the CN "shell"; (b) a substantial reduction in the wt\% of the Fe-based phases; and (c) the disaggregation of the NPs, that increases the BET area and porosity of the ECs. The Fe-based species not stabilized in the CN "coordination nests" are easily removed during $\mathbf{A}$ and are not expected to affect the ORR performance of the ECs significantly.

CV-TF-RRDE results show that the ORR performance and selectivity of here-proposed ECs are correlated with the physicochemical properties of the CN matrix (the "shell"). In particular, the disaggregation of the EC NPs upon A: (a) facilitates the elimination of $\mathrm{HO}_{2}{ }^{-}$intermediate species from the EC surface owing to a concurrent multi-site mechanism as confirmed by the concentration of $\mathrm{H}_{2} \mathrm{O}_{2}$ detected at the RRDE ring; and (b) raises the surface concentration of Fe-based complexes bound by nitrogen- and carbon-based "coordination nests", which are very active towards the ORR. Finally, the best ORR performance of here proposed ECs is found in alkaline conditions where, with respect to the $\mathrm{Pt} / \mathrm{C}$ ref., the ORR onset potential $E\left(\mathrm{j}_{5 \%}\right)$ of $\mathrm{FeFe}_{2}-\mathrm{CN}_{1} 900 / \mathrm{C}_{\mathrm{A}}$ material is $c a .38 \mathrm{mV}$ lower (0.946 and $0.908 \mathrm{~V}$ vs. RHE, respectively). Thus, the hereproposed CN-based ECs are highly promising for application in energy conversion devices such as AEMFCs and metal-air batteries.

\section{Acknowledgements}

This work was funded by the Strategic Project of the University of Padova "From Materials for Membrane-Electrode Assemblies to Energy Conversion and Storage Devices - MAESTRA". The research leading to these results has received funding from the European Union Seventh Framework Programme under grant agreement $n{ }^{\circ} 604391$ Graphene Flagship. The research leading to these results has received funding from the European Union's Horizon 2020 research and innovation programme under grant agreement $n^{\circ} 696656$.

\section{Appendix A. Supplementary data}

Supplementary data associated with this article can be found, in the online version, at http://dx.doi.org/10.1016/j. electacta.2016.11.093.

\section{References}

[1] $\operatorname{COM}(2010)$ 639, Energy 2020 - A strategy for competitive, sustainable and secure energy, European Commission, Brussels (2010).

[2] $\operatorname{COM}(2010) 677$, Energy infrastructure priorities for 2020 and beyond - A Blueprint for an integrated European energy network, European Commission, Brussels (2010).

[3] B. Dunn, H. Kamath, J.M. Tarascon, Electrical energy storage for the grid: A battery of choices, Science 334 (2011) 928-935.

[4] J.B. Goodenough, Electrochemical energy storage in a sustainable modern society, Energy Environ. Sci. 7 (2014) 14-18.

[5] Y. Shao, G. Yin, Z. Wang, Y. Gao, Proton exchange membrane fuel cell from low temperature to high temperature: Material challenges, J. Power Sources 167 (2007) 235-242.

[6] J.S. Lee, S.T. Kim, R. Cao, N.S. Choi, M. Liu, K.T. Lee, J. Cho, Metal-air batteries with high energy density: Li-air versus Zn-air, Adv. Energy Mater. 1 (2011) 34-50.

[7] V. Di Noto, T.A. Zawodzinski, A.M. Herring, G.A. Giffin, E. Negro, S. Lavina, Polymer electrolytes for a hydrogen economy, Int. J. Hydrogen Energy 37 (2012) 6120-6131.

[8] H.R. Ellamla, I. Staffell, P. Bujlo, B.G. Pollet, S. Pasupathi, Current status of fuel cell based combined heat and power systems for residential sector, J. Power Sources 293 (2015) 312-328. 
[9] K.G. Gallagher, S. Goebel, T. Greszler, M. Mathias, W. Oelerich, D. Eroglu, V. Srinivasan, Quantifying the promise of lithium-air batteries for electric vehicles, Energy Environ. Sci. 7 (2014) 1555-1563.

[10] C. Fiori, A. Dell'Era, F. Zuccari, A. Santiangeli, A. D'Orazio, F. Orecchini, Critical review of fuel cell's membranes and identification of alternative types for automotive applications, Int. J. Hydrogen Energy 40 (2015) 11949-11959.

[11] M. Granovskii, I. Dincer, M.A. Rosen, Life cycle assessment of hydrogen fuel cell and gasoline vehicles, Int. J. Hydrogen Energy 31 (2006) 337-352.

[12] P. Agnolucci, Economics and market prospects of portable fuel cells, Int. J. Hydrogen Energy 32 (2007) 4319-4328.

[13] M.A. Rahman, X. Wang, C. Wenz, High energy density metal-air batteries: A review, J. Electrochem. Soc. 160 (2013) A1759-A1771.

[14] Z.L. Wang, D. Xu, J.J. Xu, X.B. Zhang, Oxygen electrocatalysts in metal-air batteries: From aqueous to nonaqueous electrolytes, 43 (2014) 7746-7786.

[15] S. Guo, S. Zhang, S. Sun, Tuning nanoparticle catalysis for the oxygen reduction reaction, Angew. Chem. Int. Ed. 52 (2013) 8526-8544.

[16] B. Smitha, S. Sridhar, A.A. Khan, Solid polymer electrolyte membranes for fuel cell applications -a review, J. Membr. Sci. 259 (2005) 10-26.

[17] H.A. Gasteiger, S.S. Kocha, B. Sompalli, F.T. Wagner, Activity benchmarks and requirements for Pt Pt-alloy, and non-Pt oxygen reduction catalysts for PEMFCs, Appl. Catal. B Environ. 56 (2005) 9-35.

[18] I. Katsounaros, S. Cherevko, A.R. Zeradjanin, K.J.J. Mayrhofer, Oxygen electrochemistry as a cornerstone for sustainable energy conversion, Angew. Chem. Int. Ed. 53 (2014) 102-121.

[19] J.R. Varcoe, P. Atanassov, D.R. Dekel, A.M. Herring, M.A. Hickner, P.A. Kohl, A.R. Kucernak, W.E. Mustain, K. Nijmeijer, K. Scott, T. Xu, L. Zhuang, Anion-exchange membranes in electrochemical energy systems, Energy Environ. Sci. 7 (2014) 3135-3191.

[20] G. Merle, M. Wessling, K. Nijmeijer, Anion exchange membranes for alkaline fuel cells: A review, J. Membr. Sci. 377 (2011) 1-35.

[21] S.D. Poynton, J.P. Kizewski, R.C.T. Slade, J.R. Varcoe, Novel electrolyte membranes and non-Pt catalysts for low temperature fuel cells, Solid State Ionics 181 (2010) 219-222.

[22] M. Jahan, Q. Bao, K.P. Loh, Electrocatalytically active graphene-porphyrin MOF composite for oxygen reduction reaction, J. Am. Chem. Soc. 134 (2012) 6707-6713.

[23] X. Bo, Y. Zhang, M. Li, A. Nsabimana, L. Guo, $\mathrm{NiCO}_{2} \mathrm{O}_{4}$ spinel/ordered mesoporous carbons as noble-metal free electrocatalysts for oxygen reduction reaction and the influence of structure of catalyst support on the electrochemical activity of $\mathrm{NiCO}_{2} \mathrm{O}_{4}$, J. Power Sources 288 (2015) 1-8.

[24] R.L. Moss, E. Tzimas, P. Willis, J. Arendorf, L. Tercero Espinoza, Critical Metals in the Path towards the Decarbonisation of the EU Energy Sector - Assessing Rare Metals as Supply-Chain Bottlenecks in Low-Carbon Energy Technologies, Publications Office of the European Union, Luxembourg, 2013.

[25] G. Nam, J. Park, M. Choi, P. Oh, S. Park, M.G. Kim, N. Park, J. Cho, J.S. Lee, CarbonCoated Core-Shell Fe-Cu Nanoparticles as Highly Active and Durable Electrocatalysts for a Zn-Air Battery, ACS Nano 9 (2015) 6493-6501.

[26] H. Meng, P.K. Shen, Novel Pt-free catalyst for oxygen electroreduction, Electrochem. Commun. 8 (2006) 588-594.

[27] Y. Wang, H. Wu, X. Jiang, Facile-green synthesis of nitrogen-doped carbonsupported ultrafine silver catalyst with enhanced electrocatalytic property, Electrochim. Acta 108 (2013) 66-73.

[28] W. Yang, X. Liu, X. Yue, J. Jia, S. Guo, Bamboo-like carbon nanotube/ $/ \mathrm{Fe}_{3} \mathrm{C}$ nanoparticle hybrids and their highly efficient catalysis for oxygen reduction, $J$. Am. Chem. Soc. 137 (2015) 1436-1439.

[29] J. Zheng, C. Guo, C. Chen, M. Fan, J. Gong, Y. Zhang, T. Zhao, Y. Sun, X. Xu, M. Li, R. Wang, Z. Luo, High content of pyridinic- and pyrrolic-nitrogen-modified carbon nanotubes derived from blood biomass for the electrocatalysis of oxygen reduction reaction in alkaline medium, Electrochim. Acta 168 (2015) 386-393.

[30] K. Parvez, S. Yang, Y. Hernandez, A. Winter, A. Turchanin, X. Feng, K. Müllen, Nitrogen-doped graphene and its iron-based composite as efficient electrocatalysts for oxygen reduction reaction, ACS Nano 6 (2012) 9541-9550.

[31] M. Liu, R. Zhang, W. Chen, Graphene-supported nanoelectrocatalysts for fuel cells: Synthesis, properties, and applications, Chem. Rev. 114 (2014) 5117-5160.

[32] J. Zhang, S. Wu, X. Chen, M. Pan, S. Mu, Egg derived nitrogen-self-doped carbon/carbon nanotube hybrids as noble-metal-free catalysts for oxygen reduction, 271 (2014) 522-529.

[33] H. Zhu, S. Zhang, Y.X. Huang, L. Wu, S. Sun, Monodisperse $\mathrm{M}_{\mathrm{x}} \mathrm{Fe}_{3-\mathrm{x}} \mathrm{O}_{4}(\mathrm{M}=\mathrm{Fe}, \mathrm{Cu}$ $\mathrm{Co}, \mathrm{Mn}$ ) nanoparticles and their electrocatalysis for oxygen reduction reaction, Nano Lett. 13 (2013) 2947-2951.

[34] C. Zhang, K. Yanagisawa, H. Tao, A. Onda, T. Shou, S. Kamiya, Solvothermal onestep synthesis and effect of carbon on properties of ruthenium sulfide catalysts, Catal. Lett. 141 (2011) 1311-1315.

[35] Y. Feng, N. Alonso-Vante, Carbon-supported cubic CoSe 2 catalysts for oxygen reduction reaction in alkaline medium, Electrochim. Acta 72 (2012) 129-133.

[36] V. Di Noto, E. Negro, K. Vezzù, F. Bertasi, G. Nawn, Origins, Developments and Perspectives of Carbon-Nitride Based Electrocatalysts for Application in LowTemperature FCs, ECS Interface Summer 2015 (2015) 59-64.

[37] V. Di Noto, E. Negro, Development of nano-electrocatalysts based on carbon nitride supports for the ORR processes in PEM fuel cells, Electrochim. Acta 55 (2010) 7564-7574.

[38] V. Di Noto, E. Negro, S. Polizzi, F. Agresti, G.A. Giffin, Synthesis-structuremorphology interplay of bimetallic core- shell carbon nitride nanoelectrocatalysts, ChemSusChem 5 (2012) 2451-2459.
[39] V. Di Noto, E. Negro, R. Gliubizzi, S. Lavina, G. Pace, S. Gross, C. Maccato, A Pt-Fe Carbon Nitride Nano-electrocatalyst for Polymer Electrolyte Membrane Fuel Cells and Direct-Methanol Fuel Cells: Synthesis, Characterization and Electrochemical Studies, Adv. Funct. Mater. 17 (2007) 3626-3638.

[40] V. Di Noto, E. Negro, R. Gliubizzi, S. Gross, C. Maccato, G. Pace, Pt and Ni Carbon Nitride electrocatalysts for the oxygen reduction reaction, J. Electrochem. Soc 154 (2007) B745-B756.

[41] V. Di Noto, E. Negro, Pt-Fe and Pt-Ni carbon nitride-based Core-Shell ORR electrocatalysts for application Polymer Electrolyte Membrane Fuel Cells, Fuel Cells 10 (2010) 234-244.

[42] V. Di Noto, E. Negro, S. Polizzi, K. Vezzù, L. Toniolo, G. Cavinato, Synthesis, studies and fuel cell performance of core-shell electrocatalysts for oxygen reduction reaction based on a $\mathrm{PtNi}_{\mathrm{x}}$ carbon nitride shell and a pyrolyzed polyketone nanoball core, Int. J. Hydrogen Energy 39 (2014) 2812-2827.

[43] V.D. Noto, R. Gliubizzi, S. Lavina, E. Negro, G. Pace, Electrocatalysts based on mono/plurimetallic carbon nitrides for polymer electrolyte membrane fuel cells fuelled with hydrogen (PEFC) and methanol (DMFC) and for $\mathrm{H} 2$ electrogenerators ITPD2006141(A1), Breton S.p.A., priority date 18 April 2006

[44] E. Negro, K. Vezzù, F. Bertasi, P. Schiavuta, L. Toniolo, S. Polizzi, V. Di Noto Interplay between Nitrogen Concentration, Structure, Morphology, and Electrochemical Performance of PdCoNi Core-Shell Carbon Nitride Electrocatalysts for the Oxygen Reduction Reaction, ChemElectroChem 1 (2014) 1359-1369.

[45] E. Negro, V. Di Noto, Polymer electrolyte fuel cells based on bimetallic carbon nitride electrocatalysts, J. Power Sources 178 (2008) 634-641.

[46] E. Negro, S. Polizzi, K. Vezzù, L. Toniolo, G. Cavinato, V.D. Noto, Interplay between morphology and electrochemical performance of core-shell electrocatalysts for oxygen reduction reaction based on a $\mathrm{PtNi}_{\mathrm{x}}$ carbon nitride shell and a pyrolyzed polyketone nanoball core, Int. J. Hydrogen Energy 39 (2014) 2828-2841.

[47] V. Di Noto, E. Negro, F. Bertasi, G. Nawn, K. Vezzù, L. Toncelli, S. Zeggio, F. Bassetto, Electrocatalysts based on a carbon nitride matrix Breton S.p.A., priority date 28 September 2015.

[48] L. Lutterotti, Materials Analysis Using Diffraction - MAUD, v.2.33, (2010) http://maud.radiographema.com/.

[49] T.J. Schmidt, U.A. Paulus, H.A. Gasteiger, R.J. Behm, The oxygen reduction reaction on a Pt/carbon fuel cell catalyst in the presence of chloride anions, J. Electroanal. Chem. 508 (2001) 41-47.

[50] J.X. Wang, F.A. Uribe, T.E. Springer, J. Zhang, R.R. Adzic, Intrinsic kinetic equation for oxygen reduction reaction in acidic media: The double Tafel slope and fuel cell applications, Faraday Discuss. 140 (2008) 347-362.

[51] D. Van Der Vliet, D.S. Strmcnik, C. Wang, V.R. Stamenkovic, N.M. Markovic, M.T M. Koper, On the importance of correcting for the uncompensated Ohmic resistance in model experiments of the Oxygen Reduction Reaction, J. Electroanal. Chem. 647 (2010) 29-34.

[52] A. Serov, U. Tylus, K. Artyushkova, S. Mukerjee, P. Atanassov, Mechanistic studies of oxygen reduction on Fe-PEI derived non-PGM electrocatalysts, 150 151 (2014) 179-186.

[53] N. Duteanu, B. Erable, S.M. Senthil Kumar, M.M. Ghangrekar, K. Scott, Effect of chemically modified Vulcan XC-72R on the performance of air-breathing cathode in a single-chamber microbial fuel cell, Bioresour. Technol. 101 (2010) 5250-5255.

[54] N. Linse, L. Gubler, G.G. Scherer, A. Wokaun, The effect of platinum on carbon corrosion behavior in polymer electrolyte fuel cells, Electrochim. Acta 56 (2011) 7541-7549.

[55] B.H. Toby, R factors in Rietveld analysis: How good is good enough? Powder Diffr. 21 (2006) 67-70.

[56] Crystallography Open Database, http://www.crystallography.net/ (2015).

[57] C.H. Choi, C. Baldizzone, J.P. Grote, A.K. Schuppert, F. Jaouen, K.J.J. Mayrhofer, Stability of Fe-N-C catalysts in acidic medium studied by operando spectroscopy, Angew. Chem. Int. Ed. 54 (2015) 12753-12757.

[58] C.H. Choi, C. Baldizzone, G. Polymeros, E. Pizzutilo, O. Kasian, A.K. Schuppert, N. Ranjbar Sahraie, M.T. Sougrati, K.J.J. Mayrhofer, F. Jaouen, Minimizing Operando Demetallation of Fe-N-C Electrocatalysts in Acidic Medium, ACS Catal. 6 (2016) 3136-3146.

[59] S. Kabir, K. Artyushkova, A. Serov, B. Kiefer, P. Atanassov, Binding energy shifts for nitrogen-containing graphene-based electrocatalysts-experiments and DFT calculations (2016) n/a-n/a.

[60] K. Artyushkova, A. Serov, S. Rojas-Carbonell, P. Atanassov, Chemistry of Multitudinous Active Sites for Oxygen Reduction Reaction in Transition MetalNitrogen-Carbon Electrocatalysts (2015).

[61] F. Jaouen, S. Marcotte, J.P. Dodelet, G. Lindbergh, Oxygen Reduction Catalysts for Polymer Electrolyte Fuel Cells from the Pyrolysis of Iron Acetate Adsorbed on Various Carbon Supports, J. Phys. Chem. B 107 (2003) 1376-1386.

[62] A. Serov, M.H. Robson, M. Smolnik, P. Atanassov, Tri-metallic transition metalnitrogen-carbon catalysts derived bysacrificial support method synthesis, Electrochim. Acta 109 (2013) 433-439.

[63] K. Strickland, E. Miner, Q. Jia, U. Tylus, N. Ramaswamy, W. Liang, M.-T. Sougrati, F. Jaouen, S. Mukerjee, Highly active oxygen reduction non-platinum group metal electrocatalyst without direct metal-nitrogen coordination, 6 (2015) Article Number 7343.

[64] N. Ramaswamy, S. Mukerjee, Influence of inner- and outer-sphere electron transfer mechanisms during electrocatalysis of oxygen reduction in alkaline media, J. Phys. Chem. C 115 (2011) 18015-18026.

[65] B.B. Blizanac, P.N. Ross, N.M. Markovic, Oxygen electroreduction on Ag(111): The pH effect, Electrochim. Acta 52 (2007) 2264-2271. 
[66] M.R. Tarasevich, A. Sadkowski, E. Yeager, in: B.E. Conway, J.O.M. Bockris, E. Yeager (Eds.), Comprehensive Treatise of Electrochemistry, vol. 7, Plenum Press, New York, 1983 p. 301.

[67] S. Trasatti, in: V. Vielstich, A. Lamm, H.A. Gasteiger (Eds.), Reaction Mechanism and rate determining steps, vol. 2, John Wiley \& Sons, Chichester, 2003 p. $79-87$.

[68] D.B. Sepa, M.V. Vojnovic, L.M. Vracar, A. Damjanovic, Different views regarding the kinetics and mechanisms of oxygen reduction at Pt and Pd electrodes, Electrochim. Acta 32 (1987) 129-134.
[69] N.A. Anastasijević, V. Vesović, R.R. Adžić, Determination of the kinetic parameters of the oxygen reduction reaction using the rotating ring-disk electrode. Part I. Theory, J. Electroanal. Chem. 229 (1987) 305-316.

[70] N.A. Anastasijević, V. Vesović, R.R. Adžić, Determination of the kinetic parameters of the oxygen reduction reaction using the rotating ring-disk electrode. Part II. Applications, J. Electroanal. Chem. 229 (1987) 317-325.

[71] L. Lai, J.R. Potts, D. Zhan, L. Wang, C.K. Poh, C. Tang, H. Gong, Z. Shen, J. Lin, R.S Ruoff, Exploration of the active center structure of nitrogen-doped graphenebased catalysts for oxygen reduction reaction, Energy Environ. Sci. 5 (2012) 7936-7942. 